\title{
Experimental Study on Deformation and Acoustic Emission Characteristics of Arch Roadway under Different Unloading Rates
}

\author{
Gongyu Hou, ${ }^{1,2}$ Jinping Liang $\mathbb{D},{ }^{1}$ Haoyong Jing $\mathbb{D},{ }^{1,3}$ Jinxin Tan $\mathbb{D}^{1},{ }^{1}$ Yongkang Zhang $\mathbb{D}^{1}$, \\ and Xi Yang (iD
}

\author{
${ }^{1}$ School of Mechanics and Civil Engineering, China University of Mining and Technology, Beijing 100083, China \\ ${ }^{2}$ School of Mining Engineering and Geology, Xinjiang Institute of Engineering, Urumqi, Xinjiang 830091, China \\ ${ }^{3}$ China Petroleum Pipeline Engineering Corporation, Langfang, Hebei 065000, China
}

Correspondence should be addressed to Haoyong Jing; sqt1800605116@student.cumtb.edu.cn

Received 6 May 2020; Revised 12 August 2020; Accepted 2 September 2020; Published 11 September 2020

Academic Editor: Fengqiang Gong

Copyright (C) 2020 Gongyu Hou et al. This is an open access article distributed under the Creative Commons Attribution License, which permits unrestricted use, distribution, and reproduction in any medium, provided the original work is properly cited.

\begin{abstract}
The essence of roadway excavation is a process of unloading at the periphery, and the influence of unloading paths on surrounding rock damage is directly related to the selection of support design and construction technology. The real stress state of surrounding rock is often affected by different excavation conditions in the actual construction process. Therefore, a testing system of excavation and unloading model was developed to simulate the unloading process of the arch roadway under different excavation conditions. Small hollow cylindrical specimens used in this experiment were made of cement mortar. The load at the inner cavity of specimens was removed under the constant action of external pressure and axial force to simulate the real excavation unloading process. The deformation, the failure modes, and the acoustic emission evolution characteristics at the inner of specimens were obtained under unloading conditions using the strain and acoustic emission monitoring systems. The experimental results indicate that deformation laws of surrounding rock were similar under different unloading rates and initial geostresses, but failure modes and acoustic emission characteristics were quite different. Compared with that of slow unloading, the damage of surrounding rock under rapid unloading mainly accumulated after unloading, and it is easier to induce rockburst after unloading. As initial geostress increased, the occurring time of the main fracture may be delayed relatively, and the phenomenon that the distribution range of peak frequency expanded and the amplitude rose gradually can be regarded as the precursor information of the main fracture occurring. This study can be used to provide experimental support for the failure and supporting design of surrounding rock in deep underground engineering.
\end{abstract}

\section{Introduction}

With the development of the economy, the construction of underground chambers is gradually developing into the deep under the background of huge energy demand. The excavation unloading of the roadway will lead to the redistribution of the surrounding rock stress and the release of strain energy. The effects caused by different excavation unloading methods of roadway are quite different, which not only threaten the stability of the surrounding structure but also endanger the safety of the workers [1-3]. Therefore, it is of great theoretical significance and engineering value to investigate the influence of excavation unloading rates on deformation and damage evolution characteristics of roadway surrounding rock under different initial geostresses.

A large number of studies have shown that stress redistribution can cause the initiation and extension of cracks in roadway surrounding rock under excavation unloading, and the damage degree of surrounding rock is closely related to the selection of unloading stress paths and unloading rates $[4,5]$. In the absence of field tests, mechanical properties of rock, such as the strength, deformation, and failure mechanism, have been explored under different confining pressures and unloading rates through indoor triaxial tests. $\mathrm{Si}$ and Gong [5] conducted triaxial unloading tests under 
different unloading rates and confining pressures using finegrained granite cube samples to study the effects of unloading velocities and stress paths on the degree of rock failure. Li et al. [6] studied the strength and failure modes of the cube rock material through triaxial unloading tests and found that it was mainly affected by the intermediate principal stress. Zhou et al. [7] analysed the influence of unloading rates on the mechanical parameters, failure characteristics, and the brittleness of the shale through conventional triaxial unloading tests and proposed a new evaluation method of brittleness characteristics which could take the unloading effect into consideration. Du et al. [8] investigated the failure behaviors of different types of rock by using a novel testing system coupled to true-triaxial static loads and local dynamic disturbances and found that similar evolution law of cracks occurred in rock specimens. These results indicate that it is pretty important to consider the real stress state of roadway excavation when the influence of unloading stress paths on the mechanical behaviors of rocks is investigated.

The initiation and extension of fractures within rocks are accompanied by acoustic emission (AE). The parameters and frequency spectrum characteristics can reflect the evolution process of damage. AE technique has been widely used in underground engineering and a lot of research results have been obtained [9-12], which focus on studying the evolution of AE parameters in triaxial tests and assessing the inner damage of rock structures. However, there are few studies on AE characteristics related roadway excavation unloading.

In order to investigate the failure features of the surrounding rock and the rationality of supporting methods accurately, many similar simulation tests and numerical experiments were conducted in the past few years [13-18]. Gao et al. [16] studied the oscillation law of rock displacement under excavation unloading through a $3 \mathrm{D}$ geomechanical model test and proposed a new energy failure criterion. Lin et al. [17] researched the deformation, stress, and failure of roadway surrounding rock under the high geostress through a geomechanical model test and found that local rockburst occurred within the roadway. Based on the numerical calculation, Zhou and Shou [18] investigated the zonal disintegration mechanism of isotropic rock masses around a deep circular tunnel under dynamic unloading and found that the number and size of fractured and nonfractured zones significantly depend on unloading rates, in situ stress, and dynamic mechanical parameters of deep rock masses. However, excavation unloading modes in these studies are relatively single, and the numerical results are restricted by various theoretical assumptions.

Considering the real stress state of surrounding rock under excavation unloading, a laboratory model testing system that is using small hollow cylindrical specimens to simulate the excavation unloading process of roadway was independently developed by the authors [19]. The principle of the mechanical evolution process during the test is similar to that of field excavation, and it is also consistent with the mechanical model under excavation unloading in elastic- plastic theory [20]. In this paper, the influence of the unloading rate on failure mode and $\mathrm{AE}$ characteristics of the arch roadway under different geostresses were analysed using the new testing system and method. Furthermore, based on the AE parameters, the influence mechanism of the unloading effect on the damage and failure of surrounding rock were investigated, and the precondition of rockburst was revealed.

\section{Experimental Methodology}

2.1. Mechanical Parameters and Specimens Preparation. As a kind of rock-like material, the cement mortar has been widely used in rock mechanical experiments [21, 22]. Strain gauges can be buried in hollow cylindrical specimens made of this material to monitor the deformation of surrounding rock. In the test, the cement mortar was composed of cement (C40), fine sand, and various additives, in which the mass ratio of cement to sand was $1: 1.7$, and the mass ratio of water to this material was $1: 4$ in pouring. Mechanical parameters of this material measured by conventional triaxial compression tests of standard samples $(\varphi 50 \times 100 \mathrm{~mm})$ are shown in Table 1 , which are similar to those of sandstone.

The affecting scope of surrounding rock stress caused by excavation unloading is 3-5 times of the excavation radius in rock mechanics theory. Therefore, according to the theoretical boundary and practical engineering conditions, each hollow cylindrical specimen was sized at $270 \mathrm{~mm}$ height, $200 \mathrm{~mm}$ outer diameter, and $40 \mathrm{~mm}$ inner diameter of the arch cavity (Figure 1). Subsequently, strain gauges located in the middle height of the specimen were arranged in the center of the roof $(A)$, the side wall $(B)$, and the floor $(C)$. Among them, No. 1, 2, and 3 measuring points, respectively, represented the position number from the inner wall of the cavity to the outer. There were three groups of measuring points arranged from the inside to outside of the specimen to monitor radial and tangential strain. The strain gauges at No. 2 were $30 \mathrm{~mm}$ away from the inner wall.

As shown in Figure 2(a), the molds were made of hard PVC buckets with an outer diameter of $250 \mathrm{~mm}$. The strain gauges were fixed with extremely thin and sparse wire (diameter $0.2 \mathrm{~mm}$ ) mesh, which can be tightly bonded with the cement mortar materials. And they have a similar linear temperature expansion coefficient, which can be deformed together during the test. Moreover, the test results show that the strain gauges sticking to the surface of the specimen and the strain gauges embedded in the specimen have the same strain variation pattern. So there is little effect on experimental results. In addition, the position of the upper and lower ends of the specimen near the pressure plate will be affected by the boundary effect. The two ends of the specimen were oiled to reduce the boundary effect. And strain gauges were arranged in the middle of the height of the specimen so that the test data will not be affected by the end boundary effect. Based on the design dimension, the poured specimens were processed by the machine tool after $28 \mathrm{~d}$ curing (Figure 2(b)). 
TABLE 1: Mechanical parameters of cement mortar specimens and the parameter range of sandstone.

\begin{tabular}{lccccc}
\hline Material types & Cohesion $(\mathrm{MPa})$ & Friction angle $\left(^{\circ}\right)$ & Poisson ratio & Elastic modulus $(\mathrm{GPa})$ & Compression strength $(\mathrm{MPa})$ \\
\hline Cement mortar & 10.02 & 28.7 & 0.17 & 12.8 & 26.4 \\
Sandstone & $8-40$ & $20-50$ & $0.02-0.2$ & $4.9-78.5$ & $20-170$ \\
\hline
\end{tabular}

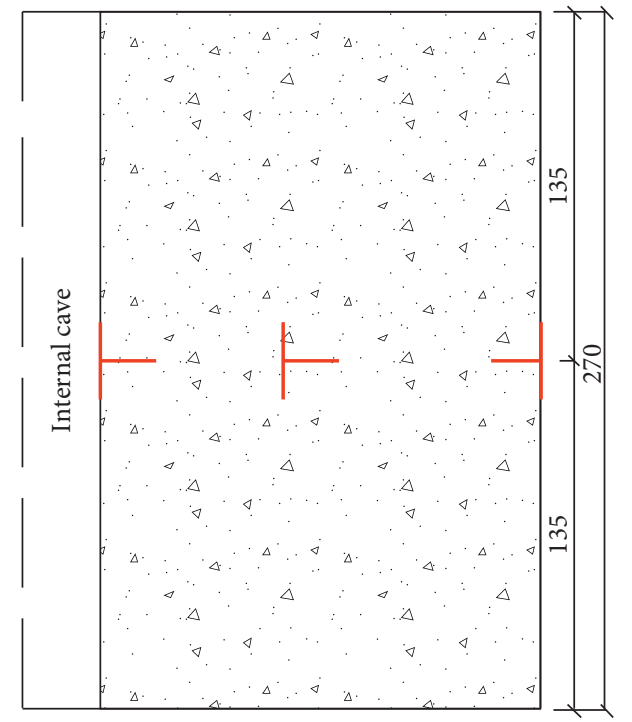

(a)

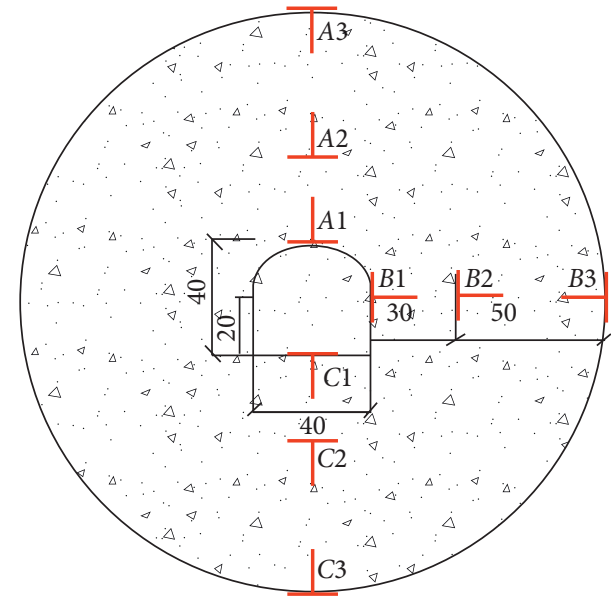

(b)

FIgURE 1: The arrangement of strain gauges. (a) The arrangement at the vertical section. (b) The arrangement at the cross section.

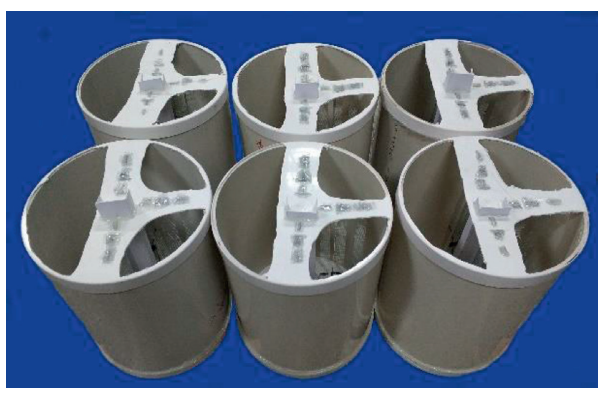

(a)

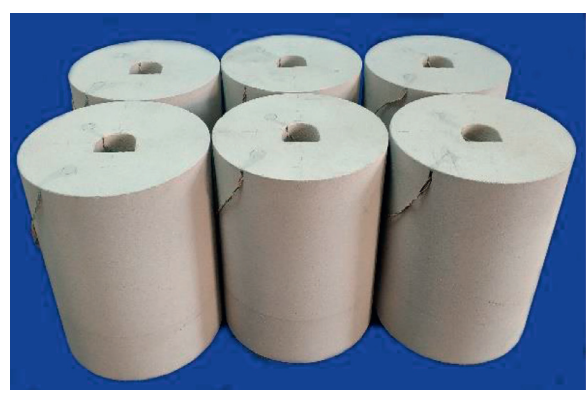

(b)

Figure 2: Production and molding of samples. (a) Molds making. (b) Processed specimens.

2.2. Excavation Unloading Testing System. The testing system consists of three subsystems, such as the loading and unloading subsystem for hollow cylindrical specimens, the $\mathrm{AE}$ monitoring subsystem, and the strain monitoring subsystem (Figure 3). The axial force, internal and external oil pressure applied to the hollow cylindrical specimen, can be controlled independently by the computer terminal. The maximum loading capacities of the axial force, internal and external oil pressure, are $3000 \mathrm{kN}, 100 \mathrm{MPa}$, and $100 \mathrm{MPa}$, respectively. As shown in Figure 4, the inner and outer surfaces of the specimen are sealed by rubber membrane at upper and lower cushion blocks to prevent silicone oil from penetrating into the specimen.

In the present study, the DS5-8B AE monitoring system (Figures 3(c) and 3(d)) was utilized to investigate the AE evolution characteristics of the specimen during the deformation and failure process. As shown in Figure 4(b), six $\mathrm{AE}$ sensors (type RS-2A, operating frequency range from $50 \mathrm{kHz}$ to $100 \mathrm{kHz}$ ) placed on the outer surface of the specimen were divided into two groups randomly, which was $50 \mathrm{~mm}$ away from the upper and lower bottom surfaces, respectively. The trigger threshold of AE was set to $30 \mathrm{mV}$ for each test, and full waveform data was recorded at a rate of $3 \mathrm{MHz}$. Furthermore, the AE output voltage was amplified to $40 \mathrm{~dB}$ gain.

2.3. Testing Procedure. The "excavation unloading" refers to a process in which the load on the inside of the roadway decreases from in situ rock stress level to zero when the 


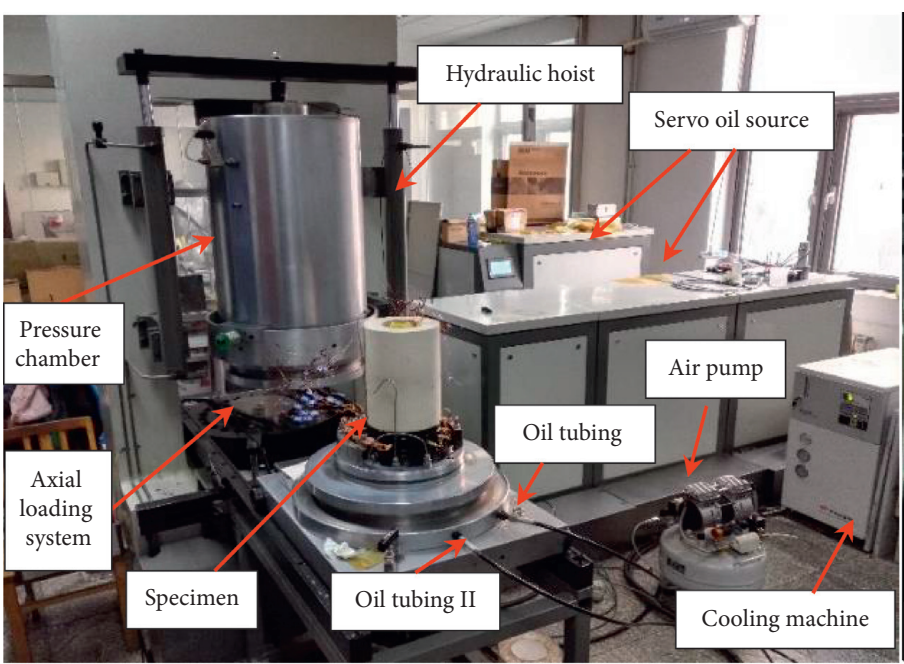

(a)

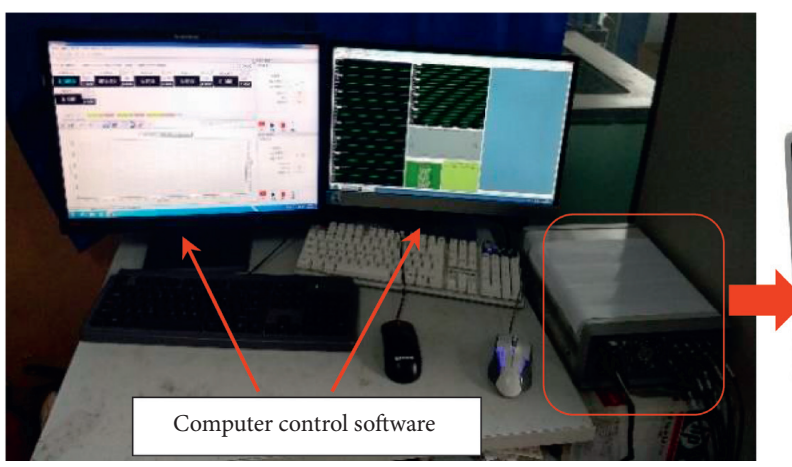

(c)

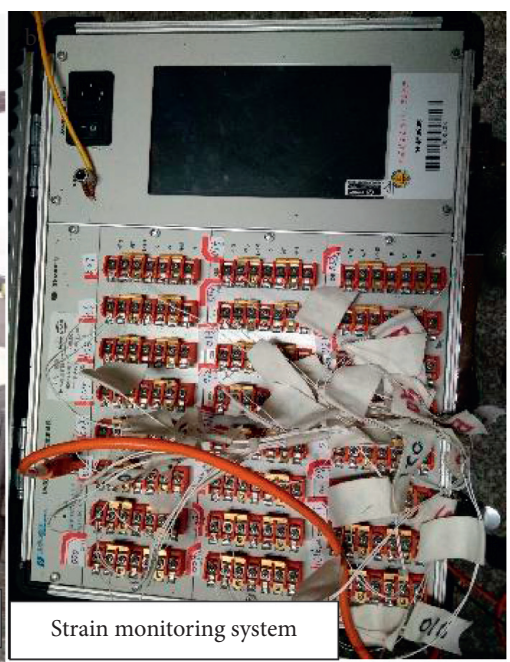

(b)

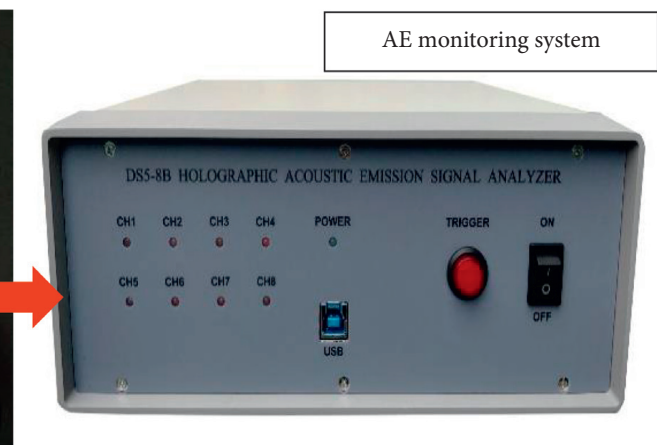

(d)

FIGURE 3: Model test system for excavation unloading of rock around the roadway. (a) The testing machine, data acquisition subsystem. (b) Static strain gauge. (c) Computer control terminal. (d) AE monitoring subsystem.

excavation body is taken out under in situ rock stress (Figure 5(a)). As shown in Figure 5(b), three-dimensional stresses applied in the specimen are the axial stress $p_{z}$, external confining stress $p_{0}$, and internal confining stress $p_{1}$, respectively. The external confining stress $p_{0}$ is regarded as the initial geostress (or in situ rock stress) because the size of the outer surface of the specimen reaches 5 times of the excavation radius, and it obeys the theoretical boundary conditions of roadway excavation. In addition, based on previous research results on the elastic-plastic theory about roadway excavation unloading [23], the axial stress $p_{z}$ was equal to the external confining stress $p_{0}$ in the process of roadway excavation unloading.

There were three applied initial geostresses $(10,20$, and $30 \mathrm{MPa}$ ) and two unloading rates (slow unloading $0.05 \mathrm{MPa} / \mathrm{s}$ and rapid unloading $2 \mathrm{MPa} / \mathrm{s}$ ) in the tests, and each specimen can only correspond to one unloading rate under one initial geostress. Before the test, the internal and external oil-filled pressure of the specimen was $2.5 \mathrm{MPa}$, which was considered as the initial stress during loading. AE and strain monitoring were carried out simultaneously in the loading and unloading process. Taking initial geostress $20 \mathrm{MPa}$ as an example, this paper shows the stress paths under two unloading rates in Figure 5(b), and specific experimental procedure consists of the following four stages:
(1) At the loading stage, three-dimensional stresses simultaneously increased to the designed initial geostress level $\left(p_{z}=p_{0}=p_{1}=20 \mathrm{MPa}\right)$ in a constant rate of $0.1 \mathrm{MPa} / \mathrm{s}$

(2) At maintaining stage after loading, the specimen was maintained for $10 \mathrm{~min}$ under the three-dimensional stresses to make the load transferred uniformly and create an initial geostress environment

(3) At the unloading stage, the internal confining stress $p_{1}$ decreased in a constant rate of $0.05 \mathrm{MPa} / \mathrm{s}$ (or rapid unloading $2 \mathrm{MPa} / \mathrm{s}$ ) to simulate the process of roadway excavation under invariable stresses $p_{z}$ and $p_{0}$

(4) At the maintaining stage after unloading, the specimen was maintained for $15 \mathrm{~min}$ under this stress level $\left(p_{1}=0 \mathrm{MPa}, p_{z}=p_{0}=20 \mathrm{MPa}\right)$ to observe static creep features of surrounding rock

Numerical data from the strain gauges were recorded to investigate the deformation of surrounding rock during testing. Positive and negative strain values represent tensile and compression of the surrounding rock, respectively. To investigate the effect of unloading on surrounding rock deformation, the beginning of the unloading stage was taken as the zero point of strain statistics, and the strain variation 

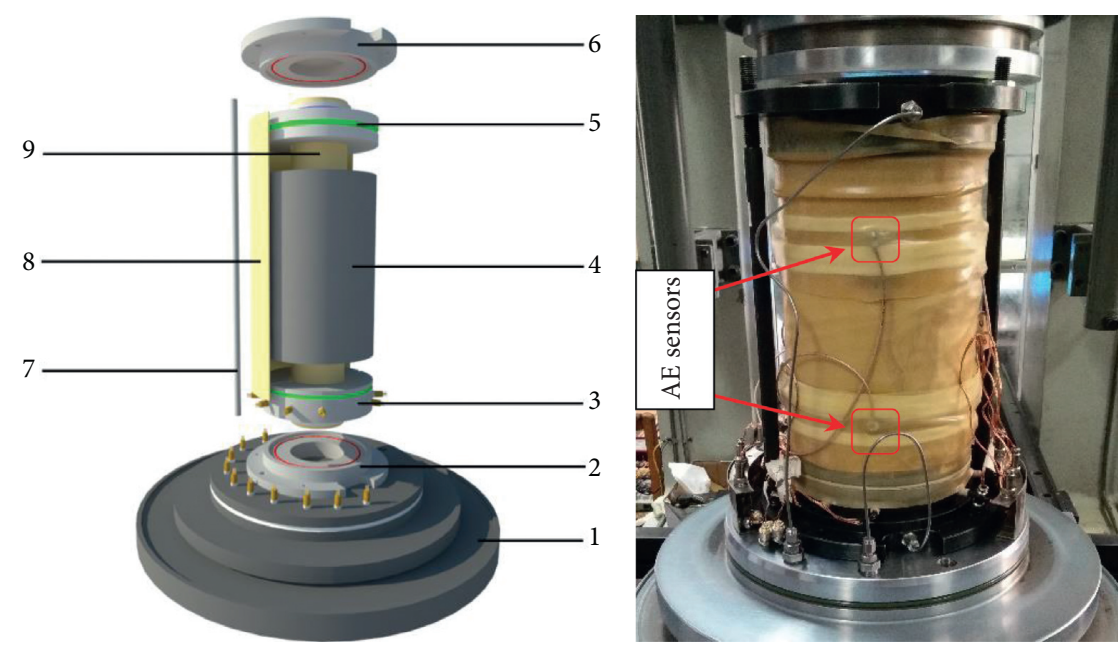

\begin{abstract}
1-Tank base; $\quad$ 6-Top seal disc II;
2-Bottom seal disc II; 7-Fixed link;

3-Bottom seal disc I; 8-External rubber sleeve;

4-specimen; 9-Inner rubber sleeve.

5-Top seal disc I;
\end{abstract}

(a)

FIGURE 4: Sealing structure of the specimen. (a) The design of sealing structure. (b) The assembled specimen.

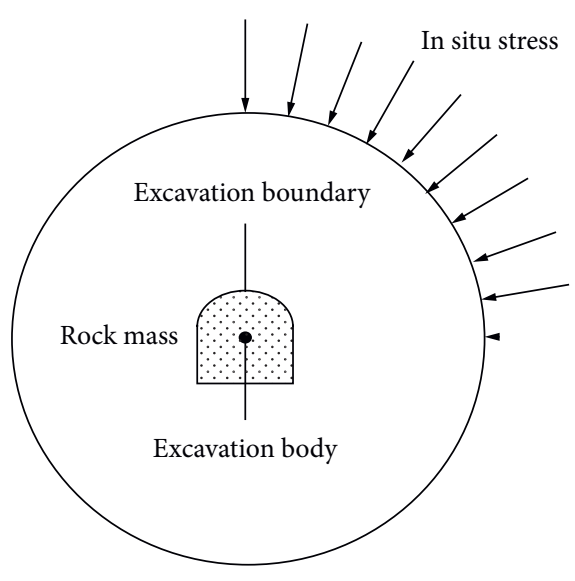

(a)

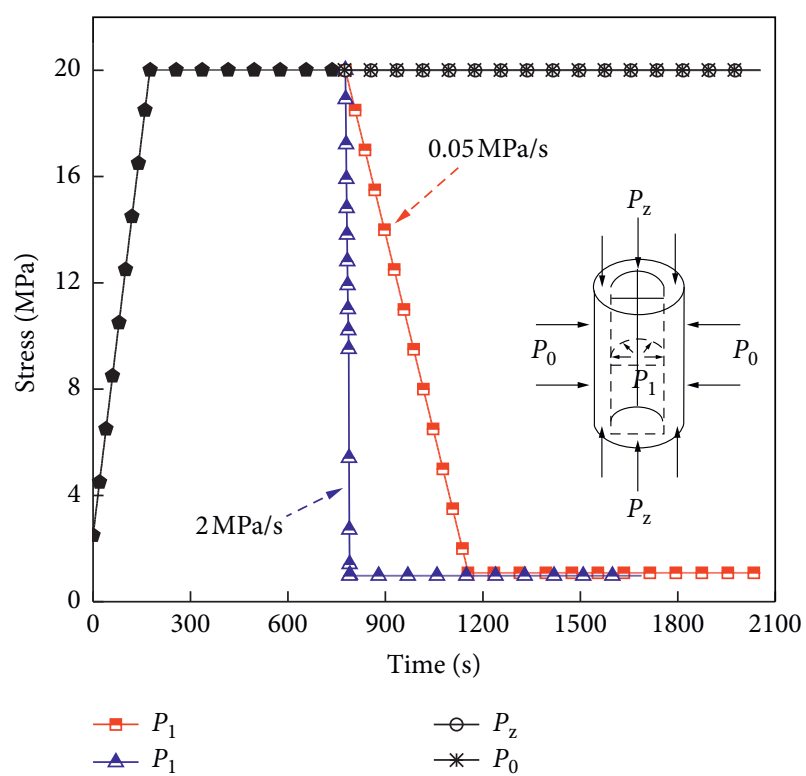

(b)

FIGURE 5: Mechanical mechanism model of the roadway under excavation unloading. (a) The theoretical model of roadway excavation. (b) Stress paths of excavation unloading test.

at the unloading stage and the maintenance stage after unloading was analysed. In this study, the excavation unloading model tests with rapid and slow unloading rates under three initial geostresses were carried out, so there were six types in total. Three groups of parallel tests were conducted for each type, and the results of one group were presented, in which the effect of surrounding rock strain and $\mathrm{AE}$ characteristics was the best.

\section{Experimental Results}

3.1. Strain Characteristics of Roadway Surrounding Rock. The strain data obtained from the static strain gage were processed, in which the beginning of the unloading stage was taken as the starting point of strain recorded. The positive sign represented the tensile strain and the negative sign represented compressive strain. Moreover, the strain 
evolution characteristics from the beginning of the unloading stage to the end of the maintaining stage after unloading were analysed in this study.

3.1.1. Strain Field of Surrounding Rock. The strain features of different measuring points with the radial depth are shown in Figures 6 and 7, in which $r$ is the distance from the position of measuring point to the center of the cavity and $r_{0}$ is the radius of the cavity $\left(r_{0}=20 \mathrm{~mm}\right)$. A radial strain refers to the strain generated along the radius direction at the measuring point inside the surrounding rock, while tangential strain refers to the strain generated in the direction perpendicular to the radius. The solid line means that the strain was generated under a slow unloading rate $(0.05 \mathrm{MPa} / \mathrm{s})$ at different measuring points, and the dotted line means that the strain was generated under a rapid unloading rate $(2 \mathrm{MPa} / \mathrm{s})$ at different measuring points. It was seen that the effects of unloading rates on surrounding rock strain were similar under different initial geostresses. The radial strain of all measuring points was tensile, whose value decreased with radial depth increasing (Figure 6). In contrast, tangential strain behavior was different from that of the radial (Figure 7). The strain was compressive at the roof, and the value also decreased with radial depth increasing, whereas it was tensile at the inner surface of the side wall and the floor and converted to be compressive at 1 2.5 time regions of the excavation radius, whose value first increased to the peak and then decreased gradually with radial depth increasing.

The strain value of all measuring points was positively correlated with initial geostresses and negatively correlated with unloading rates. Besides, the influence degree of unloading rates and initial geostresses on radial strain was weakened with the radial depth increasing.

3.1.2. Strain Evolution Process. Taking evolution features of radial strain around the floor (measuring point $\mathrm{C1}$ ) as an example, this paper shows the stress-strain relationship under two unloading rates in the unloading stage (Figure 8) and strain-time evolution characteristics in maintaining stage after unloading (Figure 9). First, the strain caused by rapid unloading stress increased slowly at the early unloading stage. Then, the stress-strain curves happened to turn with the deviatoric stress $\left(p_{0}-p_{1}\right)$ increasing, and then augmented rapidly, which indicated that the elastic strain energy in the specimen was released quickly. However, the stress-strain curves approximated a straight line under slow unloading, whose value was obviously larger than that of rapid unloading. The strain difference of two unloading rates was enlarged with the initial geostress rising. At the maintaining stage after unloading, compared with that of the slow, the creep growth rate under rapid unloading was much larger, and both curves tended to converge gradually at the end.

3.2. Failure Modes. Figure 10 presents the failure modes of hollow cylindrical specimens with two unloading rates under different initial geostresses. It can be seen that there was no apparent damage at the outer surface, but failure patterns at the inner were significantly affected by unloading rates.

When the initial geostress was $10 \mathrm{MPa}$, there were some tiny cracks generated in the inner surface of the specimen. Compared with that of the slow, the damage under rapid unloading was serious relatively, in which the abscission layer of thin sections occurred in the floor and the side wall (Figures 10(a) and 10(b)).

When the initial geostress was $20 \mathrm{MPa}$, rock blocks slabbing occurred on the floor and the side wall under rapid unloading, which was similar to rockburst. Nevertheless, the floor heave and tension cracks were generated under slow unloading, and flaky rock desquamated from the side wall. The damage degree of the roof under two unloading rates is relatively low, from which some small rock pieces peeled off (Figures 10(c) and 10(d)).

When the initial geostress was $30 \mathrm{MPa}$, the failure mode was similar to that of the $20 \mathrm{MPa}$, but the damage was more serious (Figures 10(e) and 10(f)). Rockburst could be observed on the floor and the side wall under rapid unloading. In contrast, the floor heave was obvious under slow unloading and was accompanied with a broken expand of the ruptured rock mass. Under the two unloading rates, large flaky rock stratification occurred in the roof and extended to the side wall.

In summary, under low initial geostress, the damage of rock mass is tiny and failure patterns are less affected by unloading rates. The larger the initial geostress, the more serious damage of the surrounding rock. When the initial geostress reaches a certain magnitude $(30 \mathrm{MPa})$, the failure mode is dominated by large rock blocks slabbing in the floor and the side wall under rapid unloading in this paper, which is similar to rockburst in practical engineering (Figure 11) $[17,24]$. Nevertheless, it is dominated by the heave and broken expand of ruptured rock mass under the slow.

3.3. Acoustic Emission Characteristics. The hits, the amplitude, and the frequency obtained from the AE monitoring system were processed. AE time-domain and frequencydomain analyses were conducted to systematically investigate the fracturing processes of surrounding rock under two unloading rates.

3.3.1. AE Time-Domain Characteristics. The AE method has been widely used to investigate rock failure and to quantify rock damage in many engineering applications [25-27]. Based on previous research achievements about rock failure [28], the number of cracks can be manifested by AE hits, and the rock damage was quantified by changes of AE signal characteristics. The damage variable $(D)$ can be calculated for hollow cylindrical specimens by the following:

$$
D=\frac{\Omega}{\Omega_{m}},
$$

where $\Omega$ is the number of AE hits at a certain time during the damage evolution. $\Omega_{m}$ is the cumulative amount of AE hits 


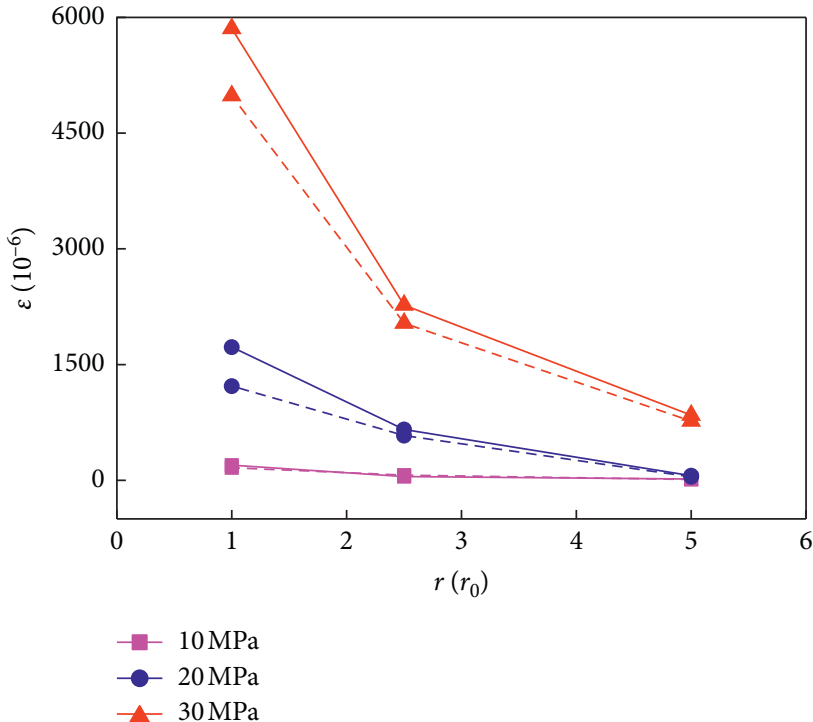

(a)

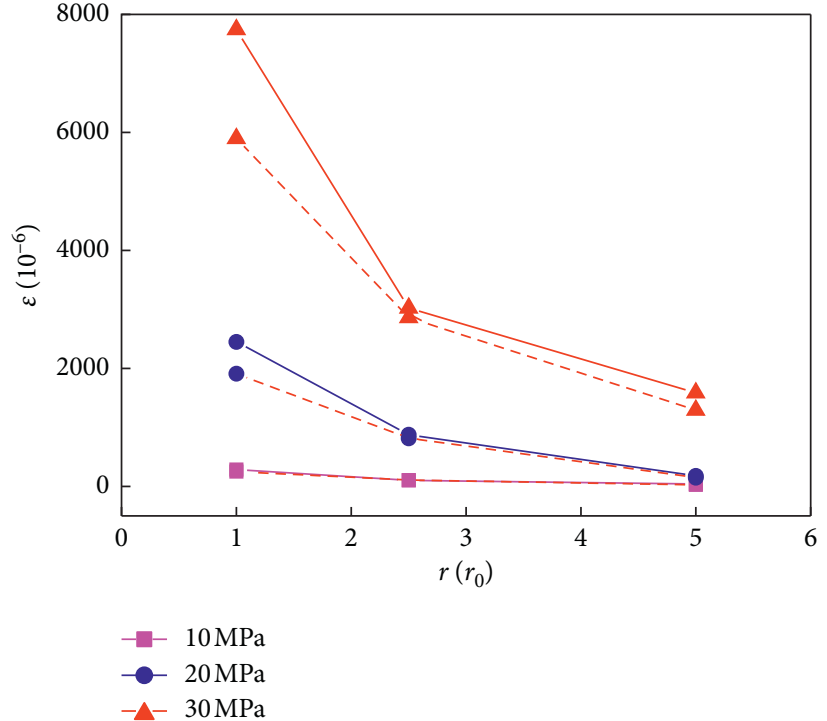

(b)

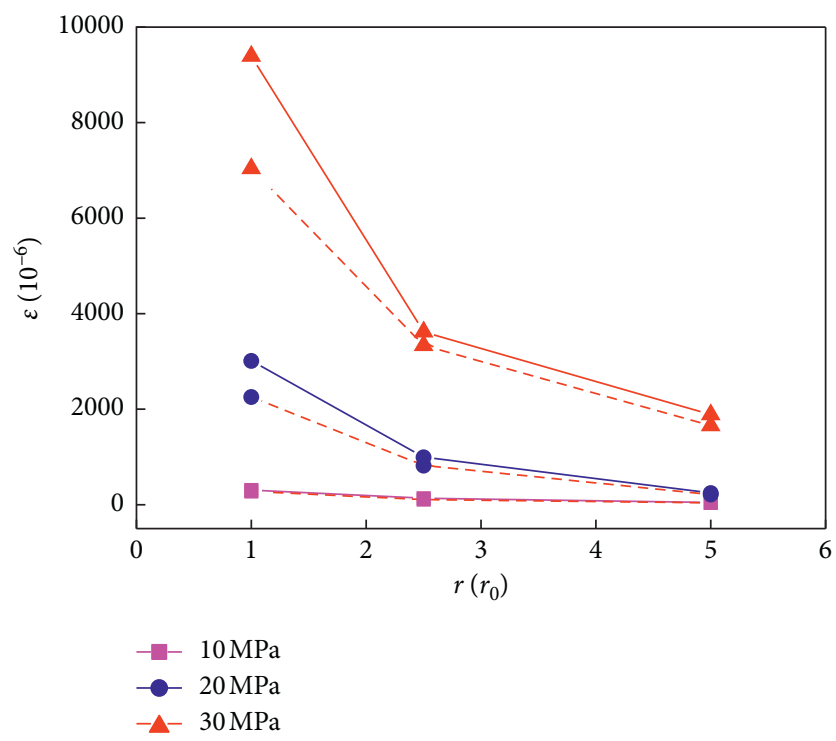

(c)

Figure 6: Radial strain characteristics of roadway surrounding rock. (a) The roof. (b) The side wall. (c) The floor. The solid line represents $0.05 \mathrm{MPa} / \mathrm{s}$; the dotted line represents $2 \mathrm{MPa} / \mathrm{s}$.

during the whole testing period. Evolution characteristics of AE hits and damage variable $(D)$ subjected to two unloading rates under different initial geostresses are shown in Figures 12-14.

It can be seen that $\mathrm{AE}$ time-domain characteristics are similar under different initial geostresses. At the loading stage, a large number of AE signals were produced due to the closure of preexisting cracks, voids, or other defects. AE hits rate increased gradually and peaked near the end of this stage, and the damage variable $(D)$ increased in a type of " $\mathrm{S}$ ". During the stress maintenance phase, AE hits rate decreased and $D$ grew slowly, which indicated that the specimen was compacted gradually.

Taking $30 \mathrm{MPa}$ initial geostress as an example, evolution characteristics of $\mathrm{AE}$ hits rate and the $\mathrm{D}$ during unloading stage and maintaining stage after unloading is shown in Figure 14. At the early and middle stages of rapid unloading, the $\mathrm{AE}$ hits rate was low, and it reached the peak rapidly at the end. The $D$ rose vertically in this stage, which indicated that propagation and transfixion of cracks occurred immediately. After unloading, the AE hits rate remained active and stabilized gradually with the maintenance time (Figure 14(a)). On the other hand, the phased division of AE time-domain characteristics during the slow unloading stage was evident, which was significantly different from that of the rapid. First, there were few AE hits at the early unloading stage and AE signals were in a "quiet period." Then, AE hits rate increased slowly with the unloading continuing, revealing that new microcracks were generated and started to grow. Subsequently, they increased in a type of jumping, 


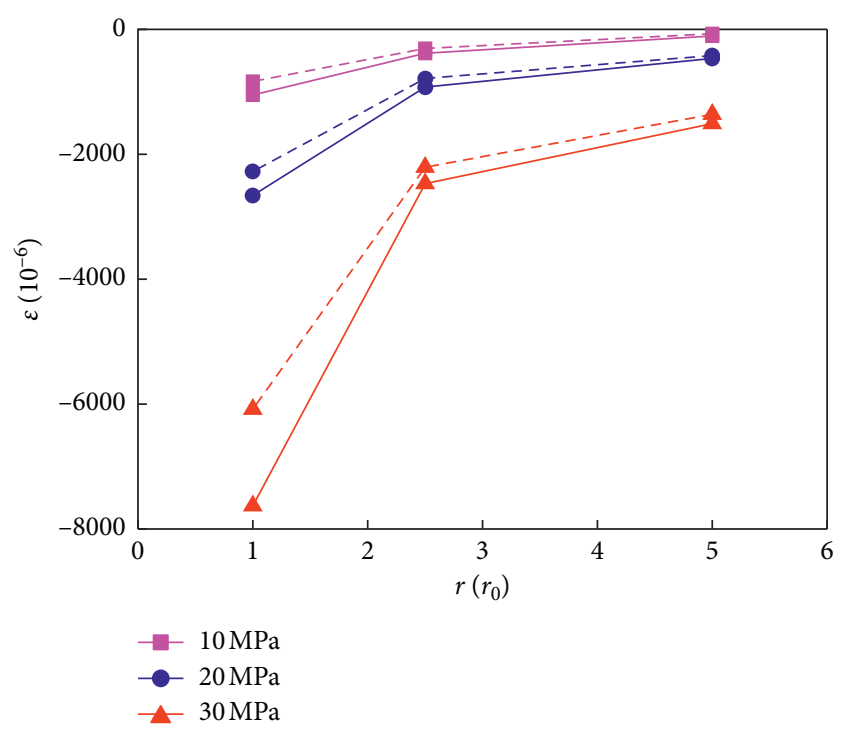

(a)

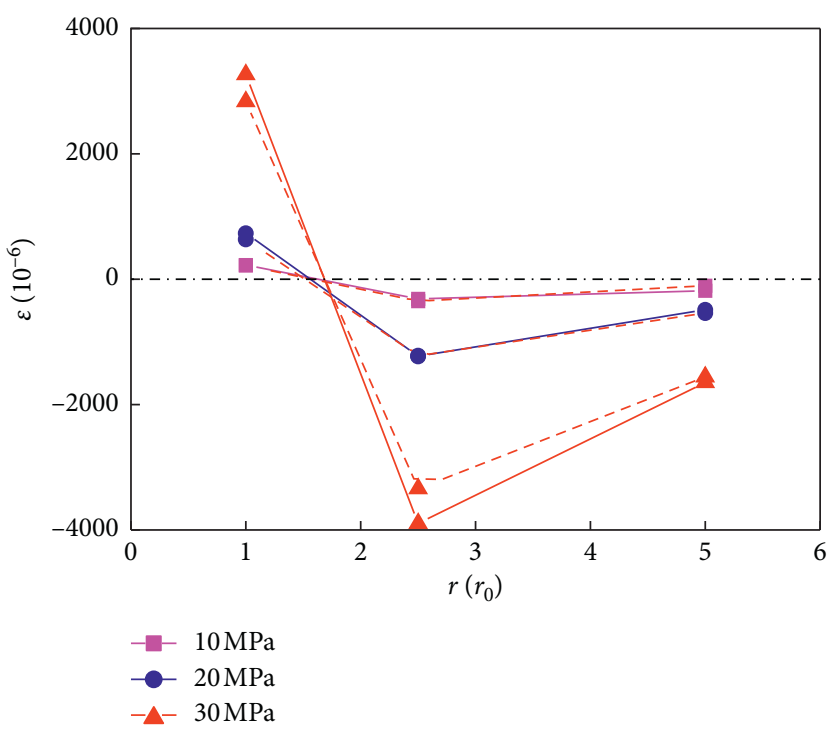

(b)

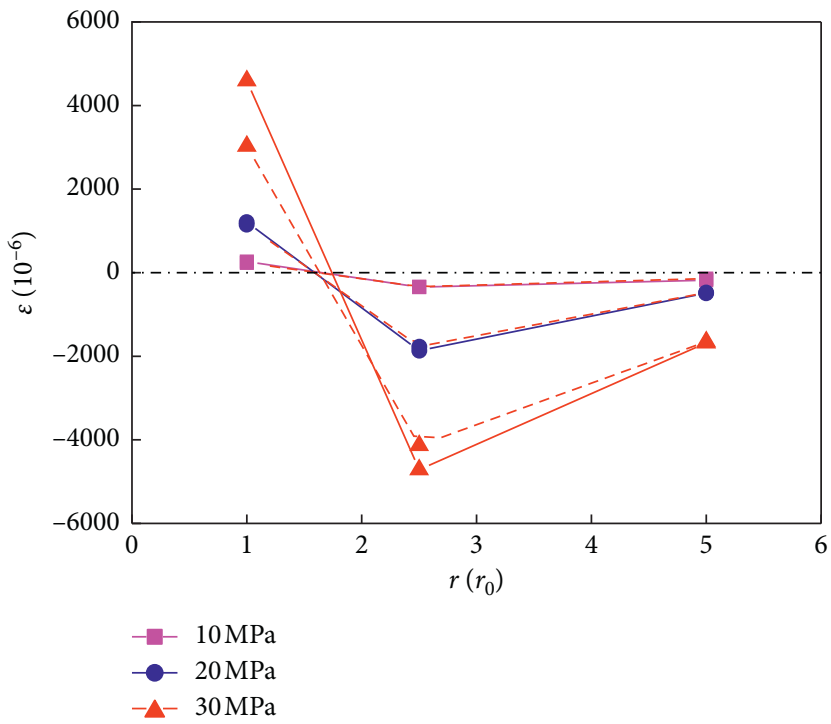

(c)

Figure 7: Tangential strain characteristics of roadway surrounding rock. (a) The roof. (b) The side wall. (c) The floor. The solid line represents $0.05 \mathrm{MPa} / \mathrm{s}$; the dotted line represents $2 \mathrm{MPa} / \mathrm{s}$.

indicating that microcracks started to extend unsteadily. Finally, AE hits rate reached the peak and the $D$ rose in exponential type, which demonstrated that the main fracture of the surrounding rock occurred. After this stage, the $\mathrm{AE}$ hits rate decreased slowly and tended to be relatively stable (Figure 14(b)).

Table 2 illustrates the effects of unloading rates on $\mathrm{AE}$ hits rate and damage variable under different initial geostresses. At the unloading stage, $\mathrm{AE}$ average hits rate of rapid unloading was much larger than that of slow unloading under the same initial geostress, indicating that the generation rate of cracks under rapid unloading was far more. The relative damage proportion of rapid unloading was much smaller than that of the slow during the unloading stage, whereas it was opposite in the creep stage after unloading, which was consistent perfectly with strain characteristics in Section 3.1.2. As the initial geostress increased, the time at the peak of the AE hits rate would be relatively delayed after the beginning of unloading, and it even appeared in a period of time after unloading.

3.3.2. AE Frequency-Domain Characteristics. AE frequencydomain characteristics were similar under different initial geostresses, so taking $30 \mathrm{MPa}$ initial geostress as an example, this paper investigated the influence of unloading rates on $\mathrm{AE}$ peak frequency and the amplitude during the unloading stage and maintaining stage after unloading. Based on the fast Fourier transform (FFT) method, Figures 15 and 16 present evolution characteristics of the peak frequency-time-amplitude 


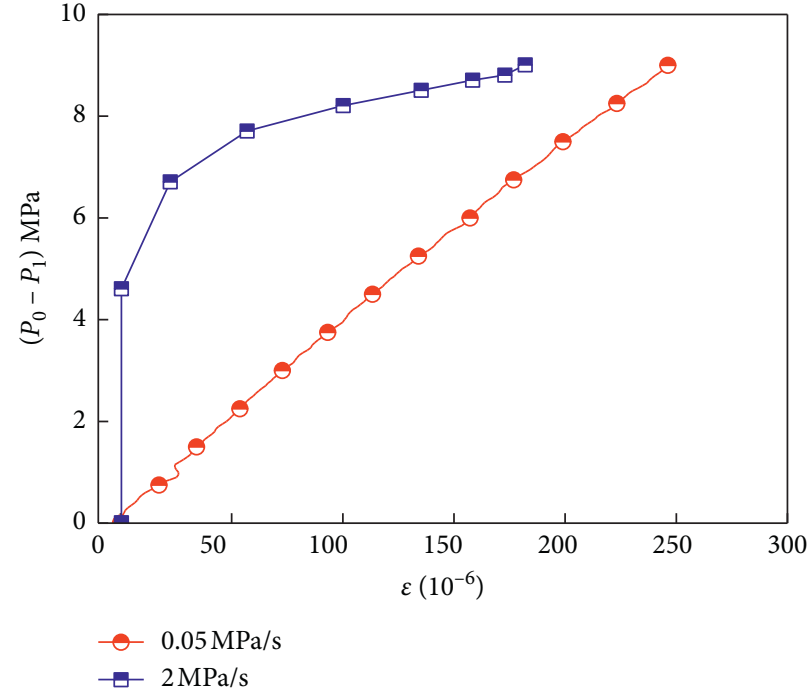

(a)

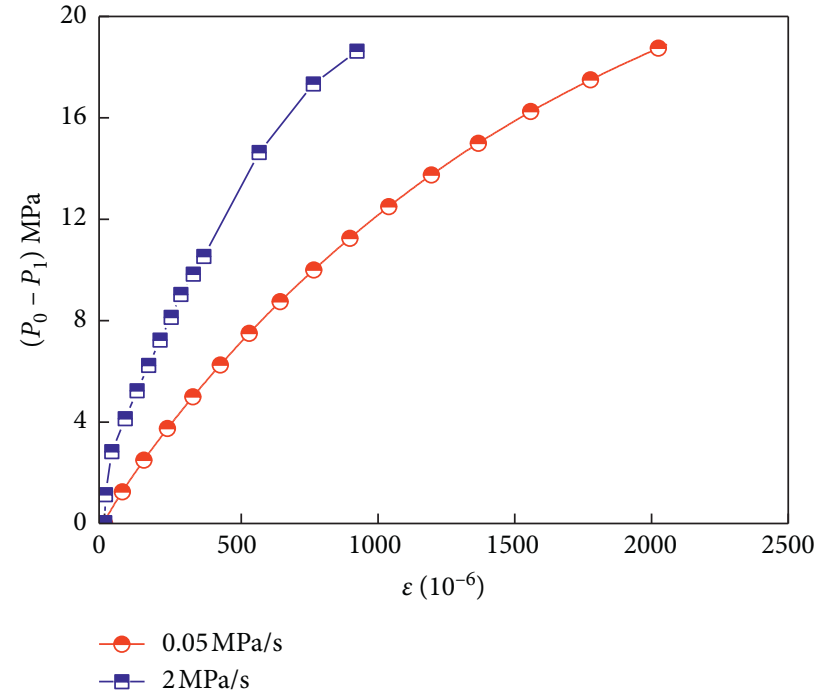

(b)

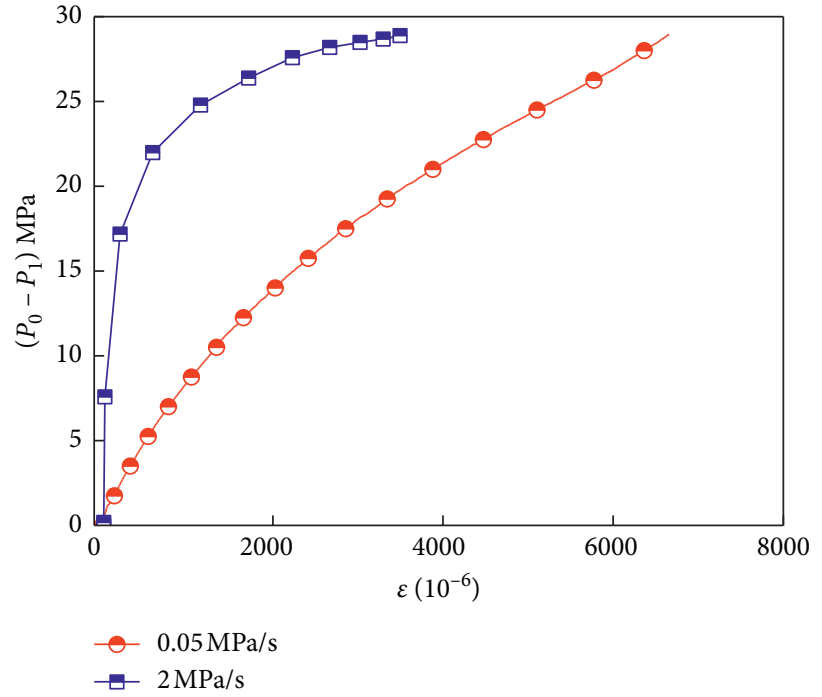

(c)

FIgURE 8: Radial stress-strain curves around the floor surrounding rock at the unloading stage. (a) $10 \mathrm{MPa}$; (b) $20 \mathrm{MPa}$; (c) $30 \mathrm{MPa}$.

obtained from the $\mathrm{AE}$ wave data under two unloading rates. Experimental results are as follows:

At the rapid unloading stage, the main fracture occurred immediately in the surrounding rock due to the instantaneous removal of stress. The distribution range of peak frequency signals was extensive, which was concentrated in $40 \sim 100 \mathrm{kHz}$ and $120 \sim 190 \mathrm{kHz}$. The amplitude of signals rose drastically near $150 \mathrm{kHz}$ and reached up to $691 \mathrm{mV}$. At the maintaining stage after unloading, high amplitude signals were also observed, and there were a small number of highfrequency signals at the end, which was concentrated in $140 \sim 160 \mathrm{kHz}$ (Figure 15).

However, compared with that of the rapid, the phased division of AE peak frequency signals was evident at the unloading stage. First, there was a small amount of $\mathrm{AE}$ signals at the early, which were concentrated in $130 \sim 160 \mathrm{kHz}$ with low amplitude. Then, signals increased gradually, whose distribution range was wider. In the end, the amplitude of signals rose slowly near $150 \mathrm{kHz}$ and reached up to $439 \mathrm{mV}$, and the peak frequency was most widely distributed at the same time. At the maintaining stage after unloading, the amplitude of signals reduced slowly, which changed to be steady at the end, and the peak frequency was also concentrated in $140 \sim 160 \mathrm{kHz}$ (Figure 16).

Overall, the evolution characteristics of $\mathrm{AE}$ amplitude and the peak frequency corresponds well to that of AE hits rate in Section 3.3.1, which also reflect the failure process of surrounding rock under two unloading rates. By comparing with $\mathrm{AE}$ frequency-domain features under two unloading rates, a large number of $\mathrm{AE}$ signals were generated in the main rupture period, in which the distribution range of peak frequency becomes wider gradually, the amplitude rose and high-amplitude signals distributed around $150 \mathrm{kHz}$. Therefore, it is believed that the expansion of the peak 

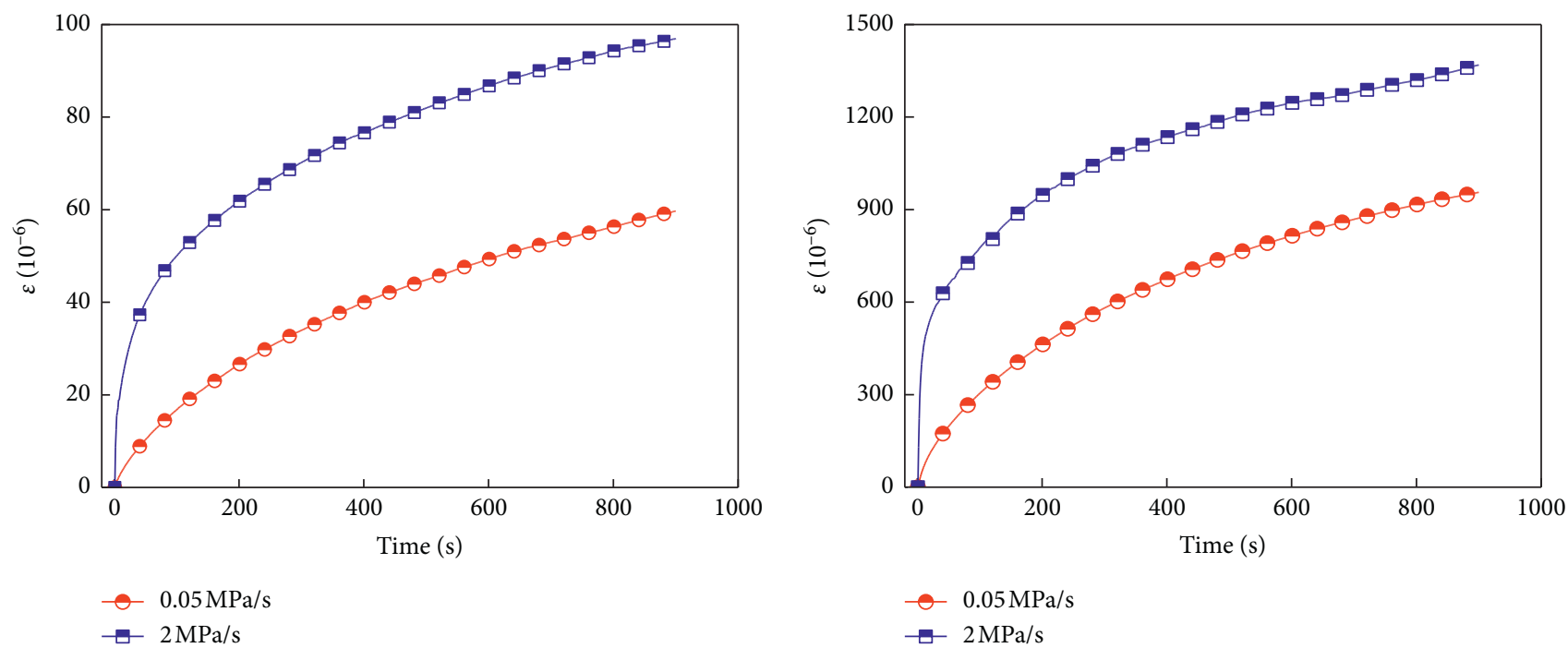

(a)

(b)

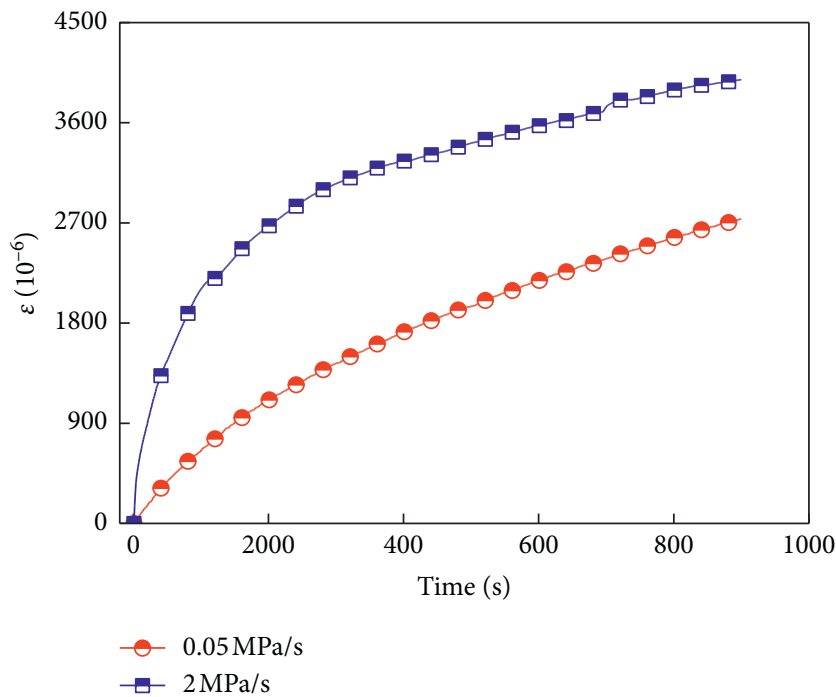

(c)

FIGURE 9: Radial strain-time curves around floor surrounding rock at the maintaining stage after unloading. (a) $10 \mathrm{MPa}$; (b) 20 MPa; (c) $30 \mathrm{MPa}$.

frequency distribution range and the gradual rise of $\mathrm{AE}$ amplitude can be regarded as precursory information of the main fracture occurring in surrounding rock at the laboratory.

\section{Analysis and Discussions}

4.1. Influence of Unloading Rates on Deformation. During the process of unloading, the free face was formed around the cavity with internal confining pressure unloaded. The surrounding rock expanded laterally under axial pressure, and it could only be developed towards the interior of the cavity due to the external confining pressure. Hence, as can be seen in Figure 6, the radial strain of surrounding rock was tensile and decreased gradually with the radial depth increasing.

It is believed that compressive stress concentration was generated in the tangential direction of the vault when the surrounding rock moved inward [29]. Meanwhile, tensile stress was generated in the tangential direction of the floor and the side wall, and the touch effect of both can cause the compression of the corner rock. With the radial depth increasing, the degree of unloading effect was weakened, and the compressive stress of the corner surrounding rock was gradually transferred to the interior of the floor and the side wall. Therefore, the tangential strain was compressive inside the surrounding rock of the floor and the side wall due to the constraints of external confining stress and axial stress. The characteristics of the strain field are consistent with that of roadway surrounding rock in actual engineering [30].

The characteristic floor radial strain proportion and the strain in the unloading stage and maintaining stage after unloading under different unloading rates are shown in Figure 17. The proportion of the strain at the unloading stage to the total strain was the highest when the initial geostress 


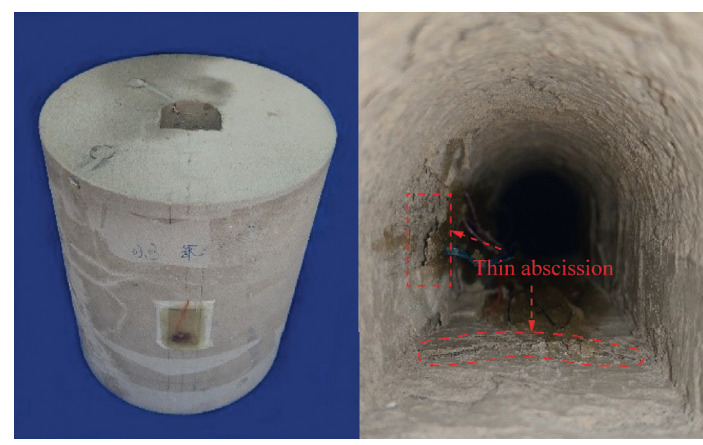

(a)

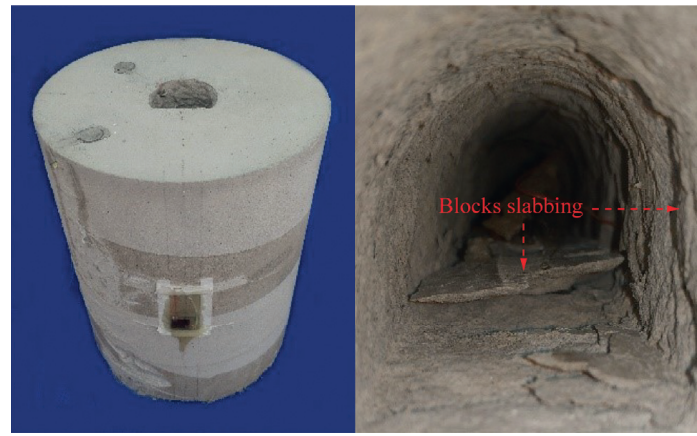

(c)

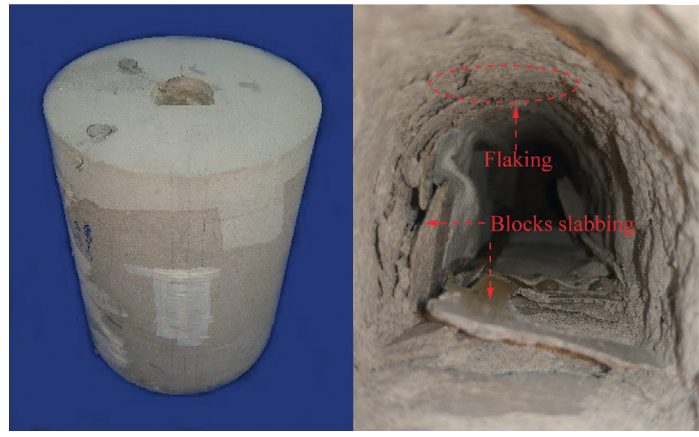

(e)

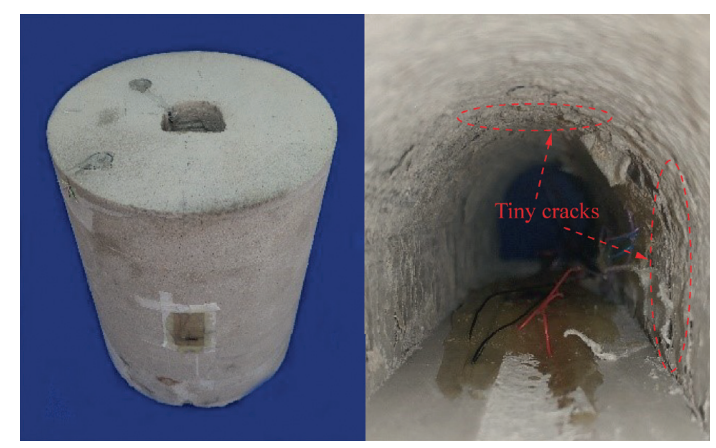

(b)

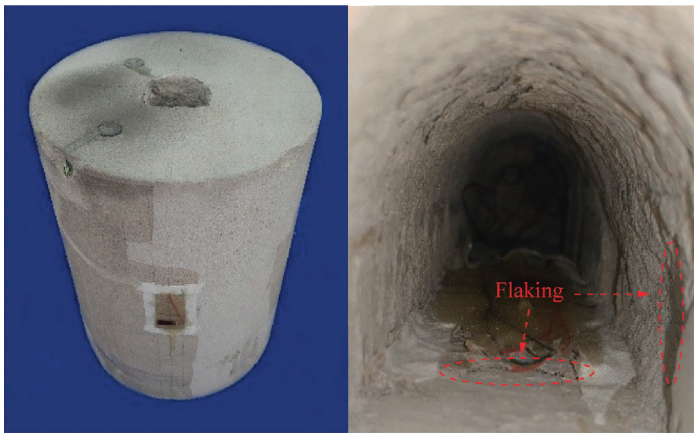

(d)

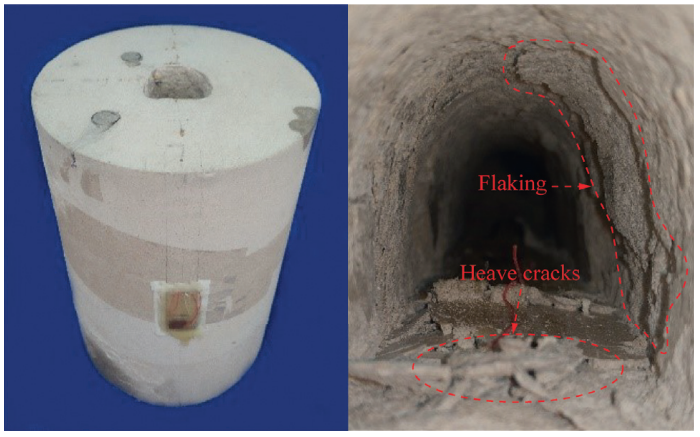

(f)

Figure 10: Failure modes of specimens under different initial geostresses and unloading rates. (a) Rapid unloading under $10 \mathrm{MPa}$. (b) Slow unloading under $10 \mathrm{MPa}$. (c) Rapid unloading under $20 \mathrm{MPa}$. (d) Slow unloading under $20 \mathrm{MPa}$. (e) Rapid unloading under $30 \mathrm{MPa}$. (f) Slow unloading under $30 \mathrm{MPa}$.

was $10 \mathrm{MPa}$. In the contrast, the proportion of strain at the maintaining stage after unloading was the lowest. With the increase of initial geostress, the proportion of strain at the maintaining stage after unloading increased relatively. However, when the initial geostress was $30 \mathrm{MPa}$, the proportion was slightly lower than that of the initial geostress $20 \mathrm{MPa}$. It is estimated that a part of the strain energy stored in the specimen was converted into the elastic energy required for stripping and falling of rock blocks and fragments. In addition, under the same initial geostress conditions, the proportion of strain at the maintaining stage after unloading of the rapid was higher than that of slow. As can be seen from Figures 8 and 9, with the stress increased, the deformation speed of the surrounding rock accelerated, and the unloading stress of the unit time caused greater deformation of the surrounding rock. That is, the greater the initial geostress is, the greater the impact on the deformation of the surrounding rock is. As shown in experimental results, the strain features of surrounding rock corresponded well with that of AE time-domain and the frequency-domain. The relative damage proportion (Table 2) under two unloading rates was similar to the strain characteristics.

4.2. Influence of Unloading Rates on Failure. Rock mechanical characteristics are the intrinsic properties of the failure mode of surrounding rock caused by excavation unloading. The rockburst grade of cement mortar in this paper was determined by the mechanical characteristics. Table 3 shows the classification standard of rockburst proneness. Uniaxial strength and elastic modulus of cement mortar were 26.4 MPa and 12.8 GPa, respectively. The elastic 


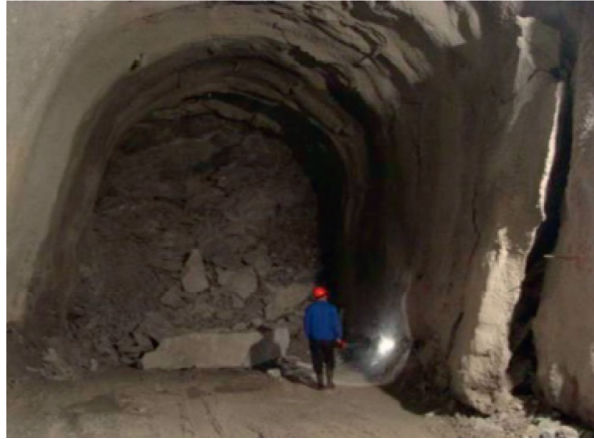

(a)

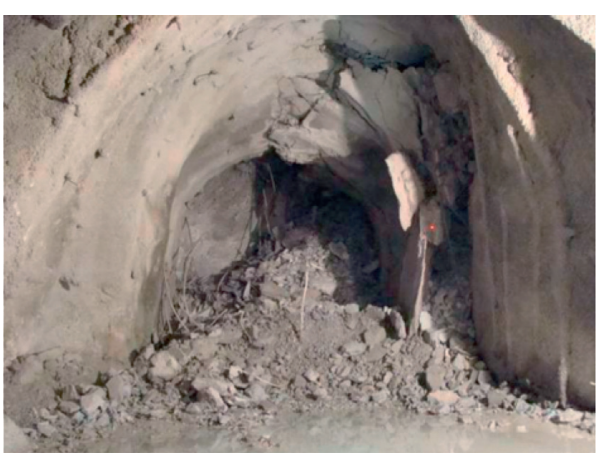

(b)

FIGURE 11: Failure characteristics of rockburst at actual arch roadway [17, 24].

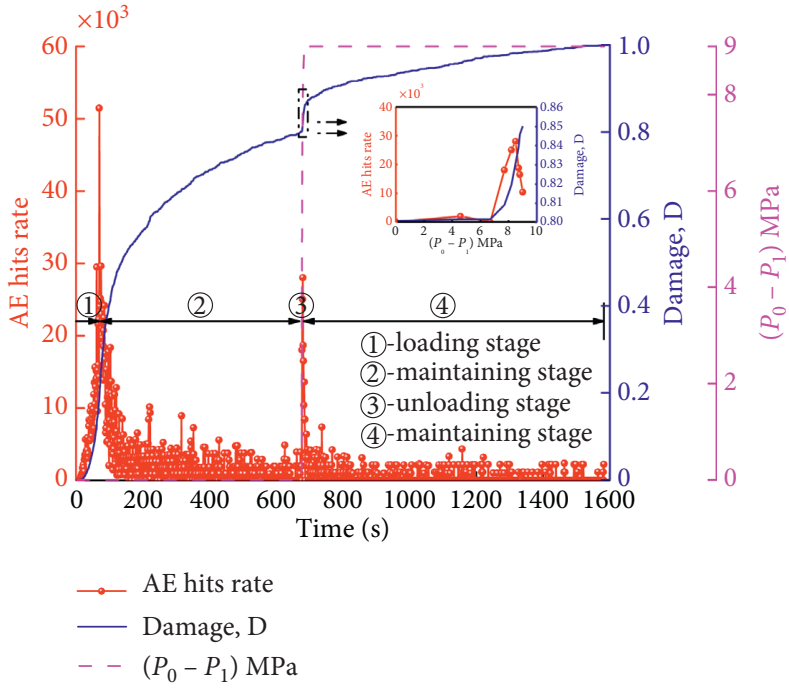

(a)

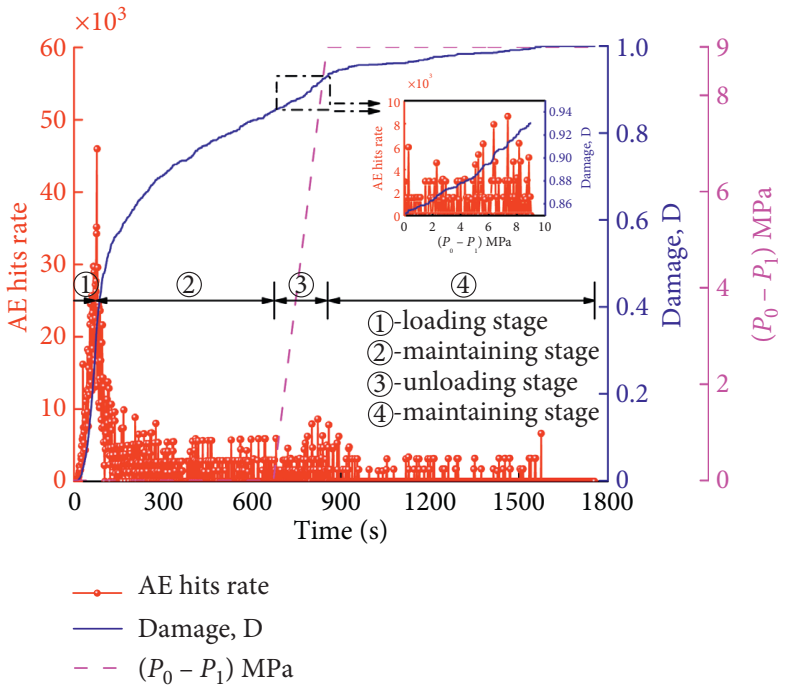

(b)

Figure 12: AE Time-domain characteristics under $10 \mathrm{MPa}$. (a) Rapid unloading. (b) Slow unloading.

strain energy index is used to identify the rockburst proneness of cement mortar [31]. The index can be calculated by

$$
U=\frac{\sigma_{c}^{2}}{2 E}
$$

where $U$ is the elastic strain energy of the material. $E$ is the elastic modulus of the material, and $U=27.225 \mathrm{~kJ} / \mathrm{m}^{3}$ is calculated. According to Table 3, it is judged that the cement mortar material in this paper has a weak rockburst proneness.

Generally, the failure modes of arch roadway are to produce large wedge at the hole wall or to produce different forms of broken area, the plastic area near the hole wall, and so on, which has been confirmed by previous chamber model tests and field tests [32, 33], and can also be explained by the existing mechanical theory of arch roadway structure [29]. When the tensile (compressive) stress is larger than the tensile (compressive) strength of the material itself, the failure occurs in the surrounding rock and the failure range is extended to a certain position where the tensile (compressive) stress caused by unloading is less than its limit value. Failure modes of surrounding rock can be well explained by the evolution characteristics of AE parameters. The experimental results show that rockburst can be induced by spalling damage of rock material [34]. In addition, rockburst may occur in weak rockburst tendency materials, which with under high ground stress and high unloading rate.

Based on the energy theory of rock damage and combined with the influence mechanism of unloading rates on surrounding rock failure studied by predecessors through triaxial tests $[5,35]$, it was analysed that a large number of microcracks in the specimen closed under the action of three-dimensional stresses during loading and maintaining stages, and this caused a large amount of elastic strain energy stored in surrounding rock. Whereafter, during the process of unloading, stress concentration occurred in the crack tip due to the stress adjustment inside the surrounding rock, and microcracks expanded, and strain energy was released 

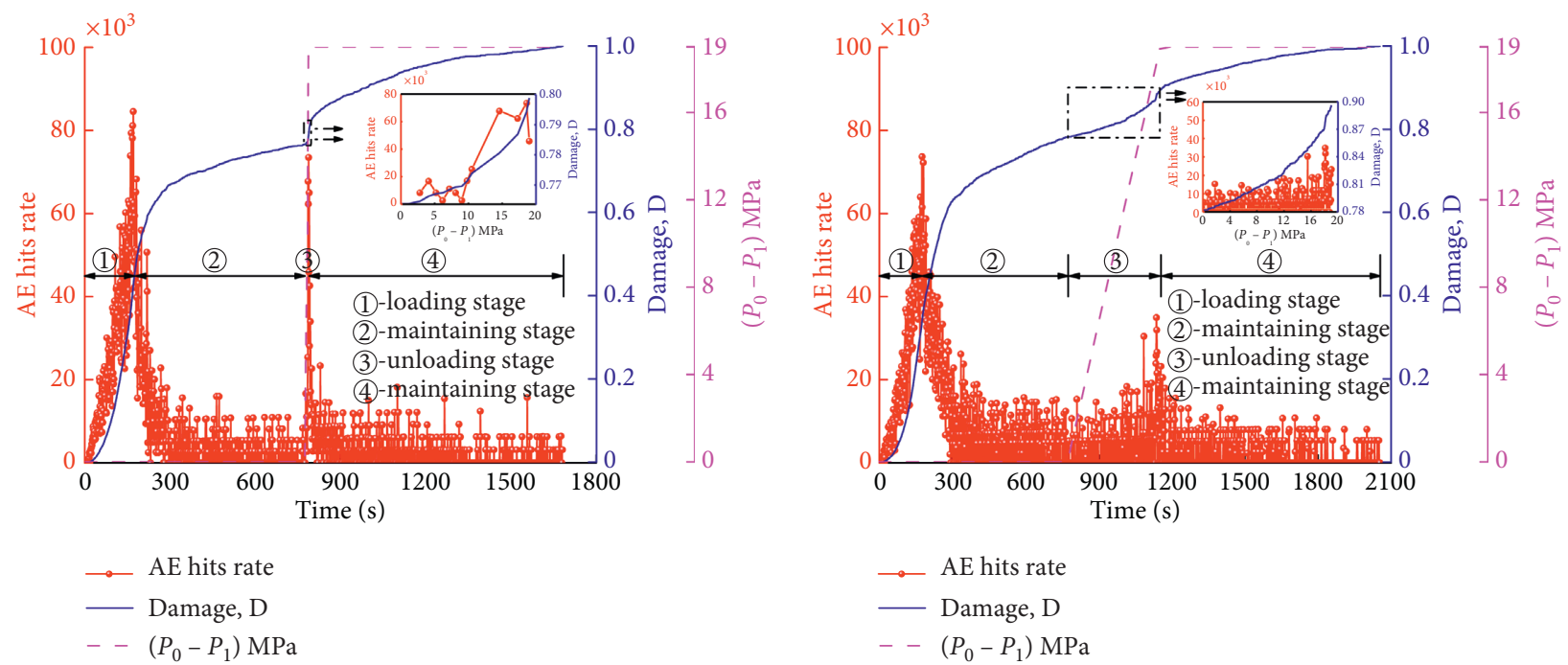

(a)

(b)

FIgure 13: AE Time-domain characteristics under $20 \mathrm{MPa}$. (a) Rapid unloading. (b) Slow unloading.

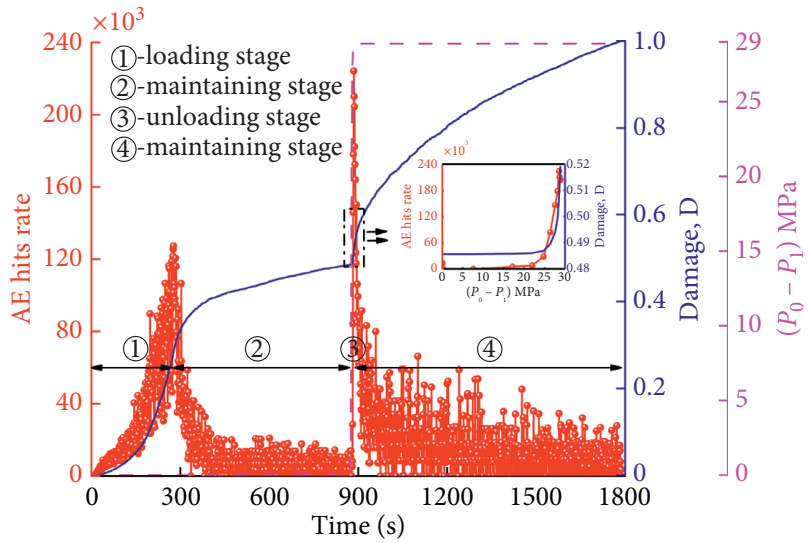

$\multimap$ AE hits rate
- Damage, $\mathrm{D}$
$--\left(P_{0}-P_{1}\right) \mathrm{MPa}$

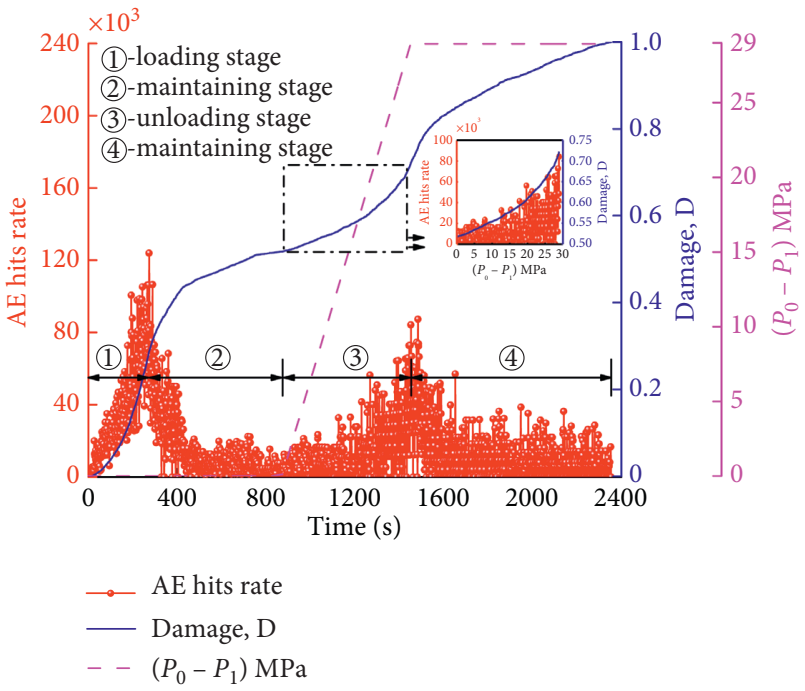

(b)

Figure 14: AE Time-domain characteristics under $30 \mathrm{MPa}$. (a) Rapid unloading. (b) Slow unloading.

TABLE 2: Effects of unloading rates on AE hits rate and damage variable under different initial geostresses.

\begin{tabular}{lccccc}
\hline $\begin{array}{l}\text { Initial } \\
\text { geostresses } \\
(\mathrm{MPa})\end{array}$ & Unloading rates & $\begin{array}{c}\text { AE average hits rate } \\
\text { at the unloading } \\
\text { stage }\end{array}$ & $\begin{array}{c}\text { Deviatoric stress at the } \\
\text { peak of AE hits rate } \\
(\mathrm{MPa})\end{array}$ & $\begin{array}{c}\text { Relative damage } \\
\text { proportion at the } \\
\text { unloading stage (\%) }\end{array}$ & $\begin{array}{c}\text { Relative damage proportion } \\
\text { at static creep stage after } \\
\text { unloading (\%) }\end{array}$ \\
\hline \multirow{2}{*}{10} & Rapid & 14.85 & $8.5(85 \%)^{1}$ & 4.9 & 8 \\
\hline \multirow{2}{*}{20} & Slow & 1.16 & $7.35(73.5 \%)^{1}$ & 3.5 & 20.1 \\
\hline \multirow{3}{*}{30} & Rapid & 25.02 & $18.6(93 \%)^{1}$ & 11.5 & 10.4 \\
& Slow & 3.48 & $18.1(90.5 \%)^{1}$ & 3.4 & 48.1 \\
& Rapid & 100.3 & $28.5(95 \%)^{1}$ & 20.5 & 27.8 \\
\hline
\end{tabular}




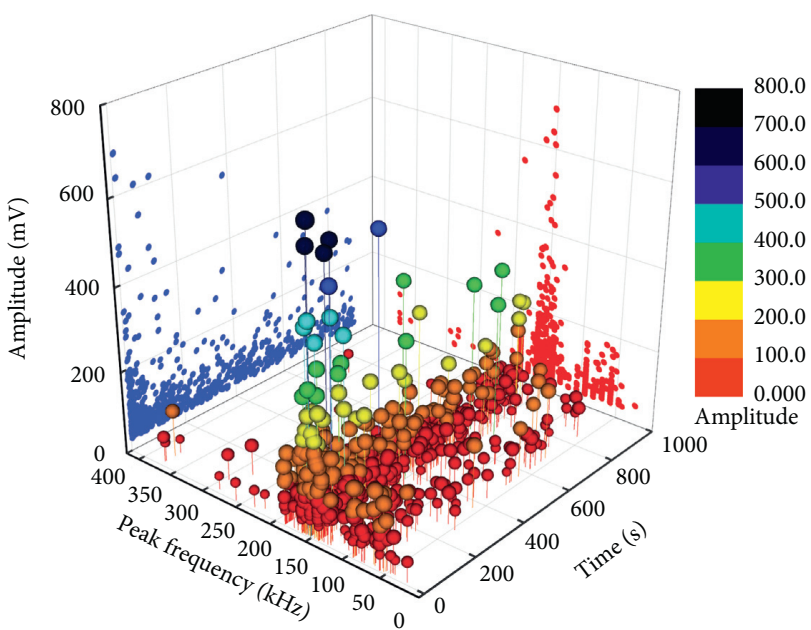

(a)

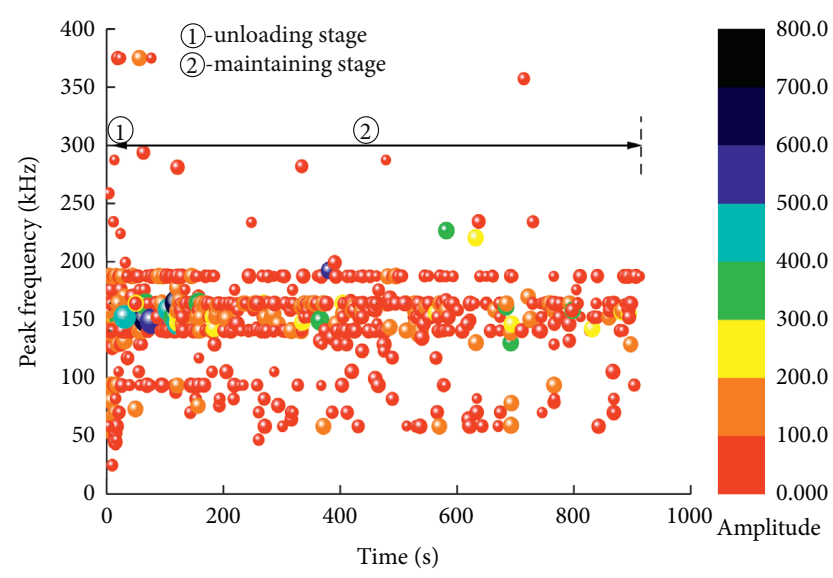

(b)

Figure 15: AE frequency-domain characteristics with rapid unloading under $30 \mathrm{MPa}$. (a) Peak frequency-time-amplitude evolution process. (b) Peak frequency-time evolution process.

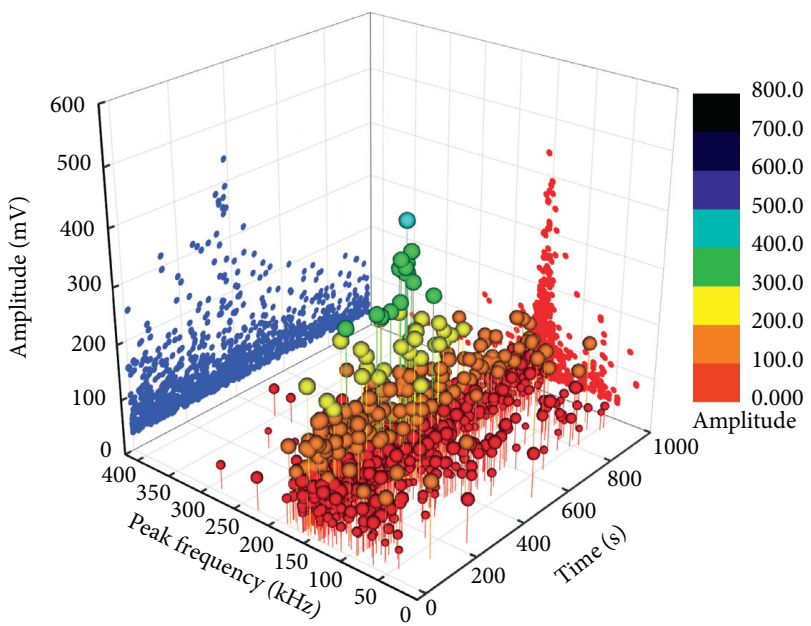

(a)

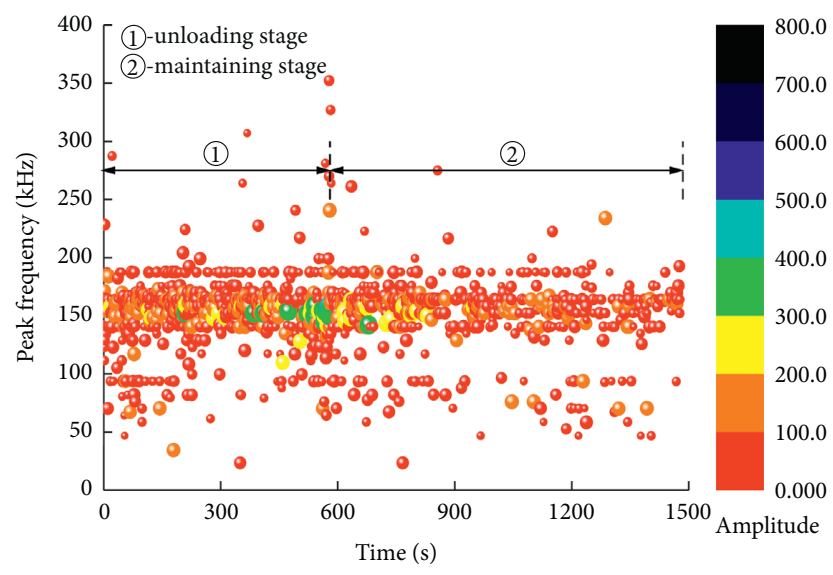

(b)

FIGURE 16: AE frequency-domain characteristics with slow unloading under $30 \mathrm{MPa}$. (a) Peak frequency-time-amplitude evolution process. (b) Peak frequency-time evolution process.

when the stress was larger than its critical strength. When the geostress was low, the energy storage in the specimens was relatively low. No matter the unloading speed was fast or slow, there will be no rockburst occurred. When the initial geostress reached a certain magnitude, a large amount of strain energy was accumulated in the surrounding rock. During the rapid unloading stage, the surrounding rock stress could not be adjusted in time at the early, and a large number of cumulative strain energy was released instantly under the cumulative deviatoric stress at the end, which caused that cracks to rapidly extend to the deep. The specimen was still affected by the unloading effect after this stage. Furthermore, some strain energy was directly converted into kinetic energy, which led to rockburst in the floor and the side wall (Figures 10(c) and 10(e)). Nevertheless, during the slow unloading stage, the stress transmitted fully under a long unloading time, the strain energy inside the surrounding rock was released slowly and fully under slow unloading. This caused a large amount of cracks initiation and propagation (Figures 10(d) and 10(f)). Thus, the strain value of slow unloading was larger than that of the rapid unloading at any deviatoric stress during the unloading stage, whereas it was opposite in the static creep stage after unloading. The compactness of the surrounding rock was raised and the ability to resist external forces at internal cracks was also enhanced due to the rise of initial geostress, which caused that the time of main fracture occurring may be delayed relatively.

In conclusion, in order to avoid rockburst, the velocity of excavation unloading should be reduced in deep mining engineering. For example, the excavation method of TBM should be used instead of the drilling and blasting method in 


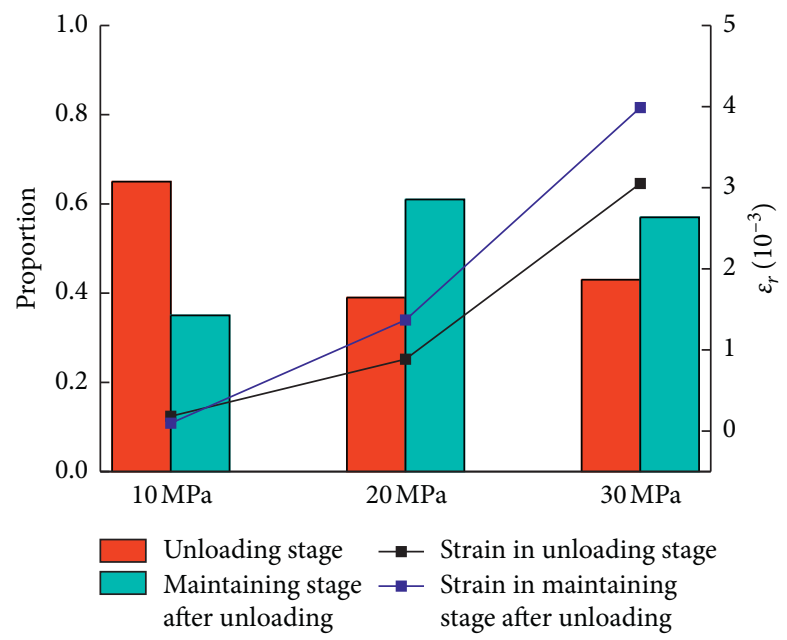

(a)

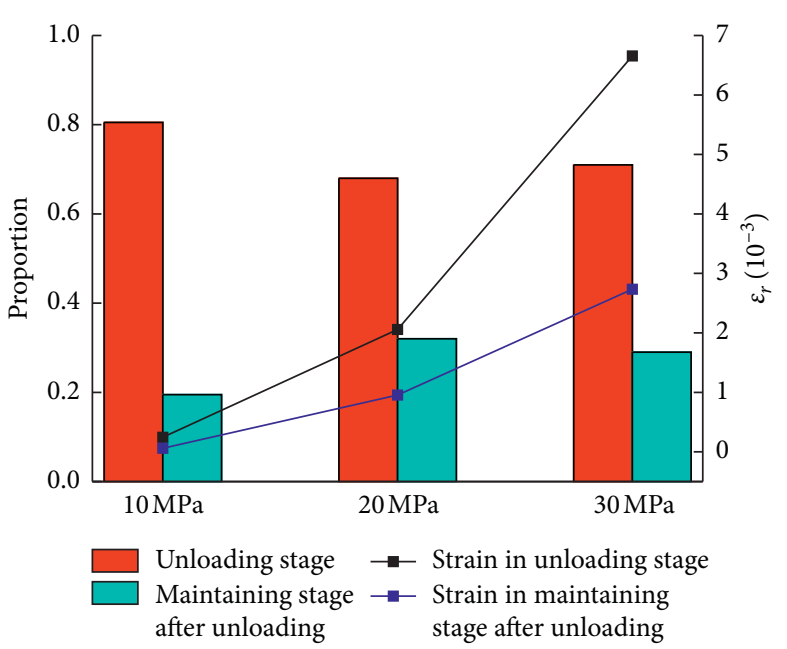

(b)

FIGURE 17: Characteristic floor radial strain proportion and strain in the unloading stage and maintaining stage after unloading. (a) Rapid unloading. (b) Slow unloading.

TABLE 3: Classification criteria for rockburst tendency [31].

\begin{tabular}{lcccc}
\hline$U\left(\mathrm{~kJ} / \mathrm{m}^{3}\right)$ & $U<40$ & $40<U \leq 100$ & $100<U \leq 200$ & $U>200$ \\
\hline Intensity of rockburst & Weak & Medium & Intensity & Extra intensity \\
\hline
\end{tabular}

actual engineering, which means to improve the efficiency of mechanical drivage and fully release the strain energy to improve the stability of the surrounding rock after excavation. In the process of roadway excavation unloading, it is necessary to support timely and effectively for heave deformation at the floor, the side wall, and the caving at the vault to inhibit the generation and development of cracks and prevent the engineering accidents.

This paper provides a new test method for investigating the deformation and $\mathrm{AE}$ characteristics of roadway surrounding rock under different excavation unloading paths. However, deep excavation is a step-by-step unloading process, which is difficult to be simulated in the laboratory [36]. Most of the simulation tests of roadway excavation and rockburst are one-time excavation. At present, few experimental systems can simulate the step-by-step excavation of roadway in a three-dimensional stress state, which is a subject of our future work.

\section{Conclusions}

In this paper, excavation unloading model experiments of the arch roadway that were conducted by the self-developed laboratory test system using the small hollow cylindrical specimens were performed to investigate the effects of unloading rates on surrounding rock deformation and $\mathrm{AE}$ features under different geostresses. Based on the experimental results, the following conclusions can be drawn:

(1) The deformation laws of surrounding rock are similar under different initial geostresses and unloading rates. The strain is tensile in the radial direction of the surrounding rock, whose value decreases with radial depth increasing. In contrast, the tangential strain characteristic is different from the radial. The strain is compressive at the roof, whereas it is tensile at the inner surface of the side wall and the floor and converted to be compressive with the radial depth increasing, whose value first increases to the peak and then decreases gradually.

(2) The strain value of all measuring points is positively correlated with the initial geostresses and negatively correlated with the unloading rates in the process of unloading. Compared with that of the slow, the strain value is smaller under rapid unloading at the unloading stage, but it is larger at the static creep stage after unloading.

(3) When the initial geostress reaches a certain magnitude, there is a conspicuous difference in failure modes under two unloading rates. On the floor and the side wall, it is dominated by large rock blocks slabbing under rapid loading, which is similar to rockburst, whereas it is dominated by the heave and broken expand of rock mass under the slow. The damage degree of roof surrounding rock is relatively low under two unloading rates.

(4) AE time-domain characteristics indicate that the main fracture occurs immediately in surrounding rock under rapid unloading. Nevertheless, the phased failure process is revealed obviously under slow unloading, which includes the initiation and 
expansion of microcracks, appearance of macrocracks, and the generation of the main fracture. The relative damage proportion during the rapid unloading stage is much smaller than that of the slow, whereas it is opposite in the creep stage after unloading. As the initial geostress increases, the time of the main fracture occurring may be delayed relatively, and it even appears in a period of time after unloading.

(5) AE frequency-domain characteristics indicate that the expansion of the peak frequency distribution range and the gradual rise of $\mathrm{AE}$ amplitude can be regarded as the precursor information of the main fracture occurring. Compared with that of the slow, the peak-amplitude of AE signals is larger under the rapid unloading and the stability is worse after unloading. As the initial geostress increases, the distribution range of peak frequency is wider gradually.

\section{Data Availability}

The data used to support the findings of this study are included within the article.

\section{Conflicts of Interest}

The authors declare that there are no conflicts of interest regarding the publication of this paper.

\section{Acknowledgments}

The authors thank the technical staff for their warm help during the preparation of samples. This work was supported by the National Key Project of the National Natural Science Foundation and Shenhua Group Corporation Limited of China (U1361210) and the National Nature Science Foundation of China (51574247).

\section{References}

[1] F. Yong, W. B. Lu, Y. H. Zhou et al., "Influence of tunneling methods on the strainburst characteristics during the excavation of deep rock masses," Engineering Geology, vol. 201, pp. 85-95, 2016.

[2] C. Y. Jin, C. X. Yang, D. Fang, and S. Xu, "Study on the failure mechanism of basalts with columnar joints in the unloading process on the basis of an experimental cavity," Rock Mechanics and Rock Engineering, vol. 48, pp. 1275-1288, 2015.

[3] F. Gao, D. Stead, and H. Kang, "Numerical simulation of squeezing failure in a coal mine roadway due to mining-induced stresses," Rock Mechanics and Rock Engineering, vol. 48, no. 4, pp. 1635-1645, 2015.

[4] X. B. Li, Z. H. Chen, W. Z. Cao et al., "Time-effect properties and mechanisms of marble failure under different unloading rates," Chinese Journal of Geotechnical Engineering, vol. 39, pp. 2518-2526, 2018.

[5] X. Si and F. Gong, "Strength-weakening effect and sheartension failure mode transformation mechanism of rockburst for fine-grained granite under triaxial unloading compression," International Journal of Rock Mechanics and Mining Sciences, vol. 131, p. 104347, 2020.

[6] X. Li, K. Du, and D. Li, "True triaxial strength and failure modes of cubic rock specimens with unloading the minor principal stress," Rock Mechanics and Rock Engineering, vol. 48, no. 6, pp. 2185-2196, 2015.

[7] X. Zhou, H. Liu, Y. Guo, L. Wang, Z. Hou, and P. Deng, "An evaluation method of brittleness characteristics of shale based on the unloading experiment," Energies, vol. 12, no. 9, pp. 1779-1802, 2019.

[8] K. Du, M. Tao, X. B. Li, and J. Zhou, "Experimental study of slabbing and rockburst induced by true-triaxial unloading and local dynamic disturbance," Rock Mechanics and Rock Engineering, vol. 49, no. 9, pp. 3437-3453, 2016.

[9] X. Li, F. Feng, D. Li, K. Du, P. G. Ranjith, and J. Rostami, "Failure characteristics of granite influenced by sample height-to-width ratios and intermediate principal stress under true-triaxial unloading conditions," Rock Mechanics and Rock Engineering, vol. 51, no. 5, pp. 1321-1345, 2018.

[10] B. Thomas, K. Murat, G. D. Nguyen et al., "Experimental study on the damage evolution of brittle rock under triaxial confinement with full circumferential strain control," Rock Mechanics and Rock Engineering, vol. 51, pp. 3321-3341, 2018.

[11] J. Peng and S. Q. Yang, "Comparison of mechanical behavior and acoustic emission characteristics of three thermallydamaged rocks,” Energies, vol. 11, no. 9, pp. 2350-2366, 2018.

[12] Y. Liang, Q. Li, Y. Gu, and Q. Zou, "Mechanical and acoustic emission characteristics of rock: effect of loading and unloading confining pressure at the postpeak stage," Journal of Natural Gas Science and Engineering, vol. 44, pp. 54-64, 2017.

[13] J. Guo, G. Feng, P. Wang, T. Qi, X. Zhang, and Y. Yan, "Roof strata behavior and support resistance determination for ultra-thick longwall top coal caving panel: a case study of the tashan coal mine," Energies, vol. 11, no. 5, p. 1041, 2018.

[14] J. B. Bai, W. L. Shen, G. L. Guo, X. Y. Wang, and Y. Yu, "Roof deformation, failure characteristics, and preventive techniques of gob-side entry driving heading adjacent to the advancing working face," Rock Mechanics and Rock Engineering, vol. 48, no. 6, pp. 2447-2458, 2015.

[15] L. X. Xie, W. B. Lu, Q. B. Zhang, Q. H. Jiang, M. Chen, and J. Zhao, "Analysis of damage mechanisms and optimization of cut blasting design under high in-situ stresses," Tunnelling and Underground Space Technology, vol. 66, pp. 19-33, 2017.

[16] Q. Gao, Q. Zhang, X. Zhang, and L. Zhang, "Geomechanical model test and energy mechanism analysis of zonal disintegration in deep surrounding rock," Geosciences, vol. 8, no. 7, p. 237, 2018.

[17] P. Lin, H. Y. Liu, and W. Y. Zhou, "Experimental study on failure behavior of deep tunnels under high in-situ stresses," Tunnelling and Underground Space Technology, vol. 46, pp. 25-45, 2015.

[18] X. P. Zhou and Y. D. Shou, "Excavation-induced zonal disintegration of the surrounding rock around a deep circular tunnel considering unloading effect," International Journal of Rock Mechanics and Mining Sciences, vol. 64, pp. 246-257, 2013.

[19] G. Y. Hou, X. R. Li, Z. D. Zhang et al., "Experimental system for simulating excavation unloading process of rock around roadway by using small cylindrical hollow specimen," Chinese Journal of Rock Mechanics and Engineering, vol. 36, no. 2, pp. 136-2145, 2017.

[20] G. Y. Hou, X. R. Li, H. Y. Liang et al., "Study on deformation and failure of high-strength gypsum surrounding rock 
specimens (thick-walled cylinder) simulating roadway excavation," Journal of China Coal Society, vol. 43, pp. 616-625, 2018.

[21] A. V. Dyskin, L. N. Germanovich, and K. B. Ustinov, "A 3-D model of wing crack growth and interaction," Engineering Fracture Mechanics, vol. 63, no. 1, pp. 81-110, 1999.

[22] L. N. Germanovich, R. L. Salganik, A. V. Dyskin, and K. K. Lee, "Mechanisms of brittle fracture of rock with preexisting cracks in compression," Pure and Applied Geophysics PAGEOPH, vol. 143, no. 1-3, pp. 117-149, 1994.

[23] G. Y. Hou and X. S. Niu, "Perfect elastoplastic solution of axisymmetric circular openings in rock mass based on Lev$\mathrm{y}$-Mises constitutive relation and D-P yield criterion," Rock and Soil Mechanics, vol. 30, pp. 1555-1562, 2009.

[24] H. Zhang, L. Chen, S. Chen, J. Sun, and J. Yang, "The spatiotemporal distribution law of microseismic events and rockburst characteristics of the deeply buried tunnel group," Energies, vol. 11, no. 12, p. 3257, 2018.

[25] A. Carpinteri, G. Lacidogna, F. Accornero, A. C. Mpalaskas, T. E. Matikas, and D. G. Aggelis, "Influence of damage in the acoustic emission parameters," Cement and Concrete Composites, vol. 44, pp. 9-16, 2013.

[26] X. G. Zhao, M. Cai, J. Wang, P. F. Li, and L. K. Ma, "Objective determination of crack initiation stress of brittle rocks under compression using AE measurement," Rock Mechanics and Rock Engineering, vol. 48, no. 6, pp. 2473-2484, 2015.

[27] M. Karakus, S. Akdag, and T. Bruning, "Rock fatigue damage assessment by acoustic emission," in Proceedings of the IC3GInternational Conference On Geo-Mechanics, pp. 82-88, Melbourne, Australia, September 2016.

[28] A. Selahattin, K. Murat, T. Abbas, N. Giang, and M. He, "Effects of thermal damage on strain burst mechanism for brittle rocks under true-triaxial loading conditions," Rock Mechanics and Rock Engineering, vol. 51, pp. 1657-1682, 2018.

[29] X. Q. Fang, J. J. Zhao, and M. Y. Hong, "Failure mechanism and control measure of roadway deformation with fractured surrounding rock in deep mine," Journal of Mining Safety Engineering, vol. 29, pp. 1-7, 2012.

[30] W. T. Li, S. C. Li, C. Xuan et al., "Mechanism and control of failure of rock roadway support in highly stressed soft rock," Chinese Journal of Rock Mechanics and Engineering, vol. 34, no. 9, pp. 1836-1848, 2015.

[31] M. F. Cai, J. A. Wang, and S. H. Wang, “Analysis on energy distribution and prediction of rockburst during deep mining excavation in Linglong Gold Mine," Chinese Journal of Rock Mechanics and Engineering, vol. 20, no. 1, pp. 38-42, 2001.

[32] P. Z. Pan, S. T. Miao, Z. H. Wu et al., "Laboratory observation of spalling process induced by tangential stress concentration in hard rock tunnel," International Journal of Geomechanics, vol. 20, no. 3, Article ID 04020011, 2020.

[33] Y. Luo, F. Gong, D. Liu, S. Wang, and X. Si, "Experimental simulation analysis of the process and failure characteristics of spalling in D-shaped tunnels under true-triaxial loading conditions," Tunnelling and Underground Space Technology, vol. 90, pp. 42-61, 2019.

[34] F. Q. Gong, Y. Luo, X. B. Li, X. F. Si, and M. Tao, "Experimental simulation investigation on rockburst induced by spalling failure in deep circular tunnels," Tunnelling and Underground Space Technology, vol. 81, pp. 413-427, 2018.

[35] W. Z. Chen, S. P. Lv, X. H. Guo et al., "Unloading confining pressure for brittle rock and mechanism of rockburst," Chinese Journal of Geotechnical Engineering, vol. 32, no. 6, pp. 963-969, 2010.
[36] G. Q. Zhu, X. T. Feng, Y. Y. Zhou et al., "Physical model experimental study on spalling failure around a tunnel in synthetic marble," Rock Mechanics and Rock Engineering, vol. 53, pp. 909-926, 2020. 